Nin
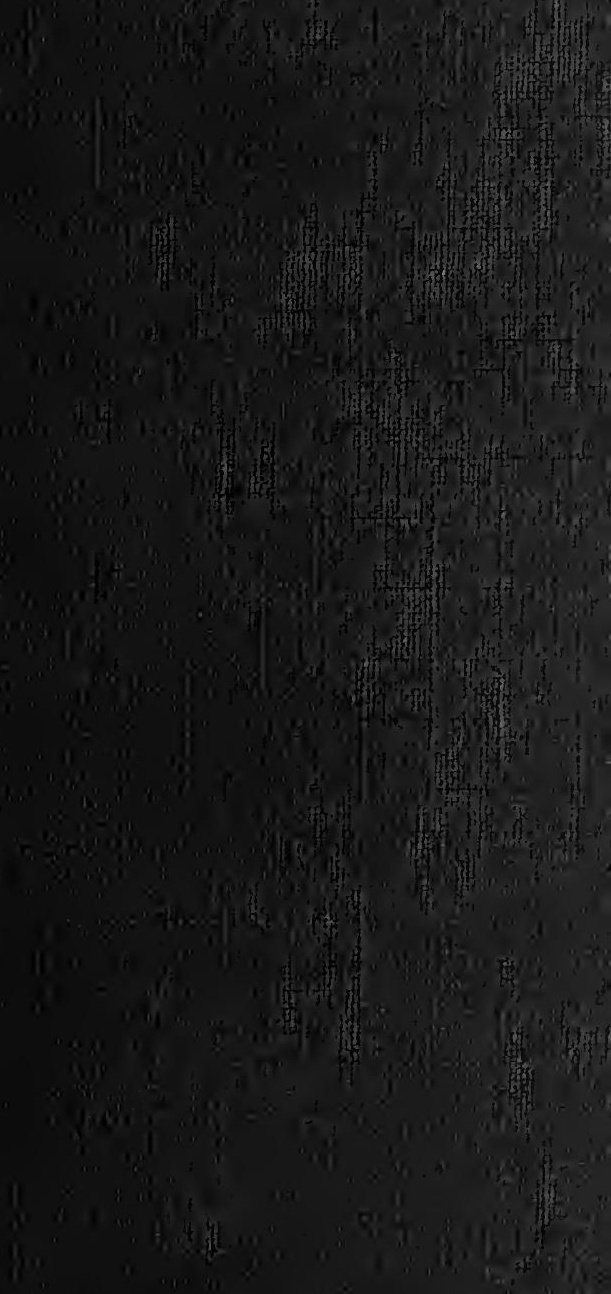

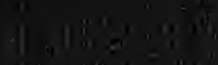




\section{LIBRARY \\ UNIVERSITY OF}

$$
\text { Enll }
$$

$S$ 
Anarvel Stackuell Aniversity of Cabf, chembranch Los Angeles, calif. 


\section{Digitized by the Internet Archive in 2007 with funding from Microsoft Corporation}




\section{PROFIT AND WAGES}




\section{.}




\title{
PROFIT AND WAGES
}

A STUDY IN THE DISTRIBUTION

OF INCOME

\author{
BY \\ G. A. KLEENE
}

PROFESSOR OF RCONOMIC, TRINITY COLLEGE, HARTFORD, CONN,

\author{
ANru Uark \\ THE MACMILLAN COMPANY \\ I9I6
}


Copyright, 1916,

BY THE MACMILLAN COMPANY.

Published November, 1916. 


\section{PREFACE}

Though its abstract and intricate character has made it an esoteric discipline, the theory of distribution demands the consideration of every serious student of affairs. No fundamental conception of our most important economic problems is attainable except in relation to the factors governing the distribution of income. Unless resigned to superficial views, we cannot, therefore, maintain a passive attitude toward the unsettled state of economic doctrine. In the face of continued failure, neither discouragement nor scepticism should halt the struggle for a definite and accepted theory of distribution. May the publication of this book contribute something to the will to master the difficulties of the problem.

The author is under obligation for permission to use parts of an article published in the Quarterly Journal of Economics for February, 1912. He is also under great obligation to his wife for criticism and assistance in revision and proof-reading, and to his friend, $\mathrm{Mr}$. Edward Porritt for helpful counsel. 



\section{TABLE OF CONTENTS}

Chapter I. Introduction.

Definitions of distribution and income, r. Concept of psychic income not of service to present inquiry, $\mathbf{r}$. Differences in method of investigation according as the subject is the distribution of wealth or the distribution of income, 2. The method of economic theory, 3. Hypothetical assumptions to be made and limitations of our inquiry, 5 . Reasons why our inquiry must be largely critical, 7 .

General Outline of Subject - The parties who share in the total product of society, 8. Different concepts of capital, 9. Capital regarded as subsistence advanced to labor the most fruitful concept for the theory of distribution, Ir. Distinction between differential and marginal income, 13. First stage in our analysis of distributive process the separation of differential gain from marginal income, 15. The second stage the division of marginal income between capitalist and laborer, i6. Three different methods by which it has been attempted to explain this division, 18.

Chapter II. Böhm-Bawerk's Theory of Interest.

Reasons for beginning a critical study of the problem with Böhm-Bawerk's theory, 20. Böhm-Bawerk's fundamental concept, 2I. Three reasons for preference for present over future goods given by Böhm-Bawerk, 22. The technical superiority of present good no direct ground for preference for present goods but possibly an indirect one, 25. Böhm-Bawerk failed to give a unitary explanation of interest, 28 .

\section{Chapter III. The Time-Preference Theory.}

Attempt to base interest theory on first two grounds of preference mentioned by Bōhm-Bawerk, 29. Do these play an actual part in saving and investment? 30. Defini- 
tion of time-preference, 33. Transition from earlier idea of abstinence to that of time-preference, 35. No postponement of consumption of capital in actual investment, 36 . Is there an exchange of present for future goods? 39. A less objectionable form of time-preference theory, 43. The consumption loan, 45. The purchase of durable goods not explained by time-preference theory, 46. The reductio ad absurdum of the time-preference theory, 47. Sceptical reaction against theories based on subjective valuations, 49. Excessive rationalism of time-preference theory, 51. Time-preference not a direct determinant of the rate of interest, 53.

Chapter IV. The Abstinence Theory.

The abstinence theory treats only of supply of capital and does not give a complete explanation of the income of capital, 55. Accumulation of capital without subjective cost, 56. Idea of marginal savings, 57. Ambiguities of a formulation of the theory in terms of demand and supply, 59. The two fundamental propositions of the theory, $6 r$. Criticism of idea that changes in supply of capital regulative of rate of return are brought about by marginal savers, 62. Prime factors determining supply of capital are objective, not subjective, 68. Supply of capital, on the whole, tends to rise with increase in rate of return, 70. Does not decrease as rate of return declines, 71. Factors which prevent extinction of capitalist income, 73. Only extreme changes in rate of interest affect determination to save, 75. Theory of rate of capitalist income must emphasize objective factors, 77. Does abstinence theory explain existence of interest? 79 .

Chapter V. The Productivity Theory of Interest.

The specific productivity theory, 82. Difficulties of imputing a specific product to capital, 82. Vicious circle in deriving value of capital goods, 85 . Productivity theory does not show how interest on sums spent for wages is derived, 87. Difficulties growing out of concept of capital 


\section{TABLE OF CONTENTS}

and restricted view of productive process, 87. A form of productivity theory suggested by Böhm-Bawerk and Landry, 92. The assumption of a normal lack of capital made by this theory, 94. The theory at bottom almost the same as the specific productivity theory and encounters similar difficulties in determining value of capital invested, 95. Importance of the theory, 97.

Chapter Vi. The Essentials of a Theory of Profit and INTEREST.

Relation of four quantities (gross income, net income, rate, and capital) expressed in two equations, 99. None of theories so far examined has explained, or is justified in assuming as accounted for, more than one quantity, Ioo. Necessity of accounting for value of 'capital independently of amount of product or rate of profit, ror. Capital consists of wages, and profit of capital is a residual income, 102. Name to be given to our theory, 105. What prevents fall of prices from extinguishing share going to capital? 108. What keeps labor from getting entire marginal product of industry? rog. How is surplus value growing out of a series of processes controlled by different entrepreneurs distributed at a uniform rate to every part of investment made by each entrepreneur? I Io. Theory here proposed assumes as given factors transmitted from pre-capitalistic times, i I 2.

Chapter VII. The Theory of Wages. The Supply of LABOR.

Relation of theory of wages to theory of income of capitalist, I 14. Wage theories which might form basis of a residual claimant theory of profit and interest, 115. Malthusian basis of subsistence theory, I 6 . Relation between standards of living and wages, I 17. Arbitrary character of assumption of a natural wage, 118. Marx's criticism of subsistence theory, I19. Immigration a disturbing factor, I 19. Need of a theory of demand for labor felt by classical economists, 120. Rise of standard of living of wage-earners and its bearing on subsistence theory of 


\section{TABLE OF CONTENTS}

wages, I2I. Conditions under which subsistence theory has some validity, I22. How supply price of labor is determined, I24. Why geographical differences in wages correspond to differences in productivity, 126.

Chapter VIII. The Theory of Wages. The Demand for LABOR.

The wages fund doctrine suggests a collective exchange, 128. Necessity of laborer and employer coming to terms, 129. Does possibility of substituting machines for labor show that there is no definite wages fund? r3o. Under static conditions and when production period of maximum efficiency has been reached, there is a definite wages fund, 133. Bōhm-Bawerk's wages fund theory, r35. Is wages fund capable of quick expansion? 137. When viewed as a money fund, 138 . When regarded as real income, I39. The bargain theory of wages, I4I. Wages fund theory only possible explanation of general level of wages, $\mathbf{1 4 2}$.

Criticism of Productivity Theory of WagesErroneous assumption in regard to expansibility of demand for labor, I 44. Productivity explains comparative wages only, I46. Can wages be paid out of current product? 149. Productivity determines wages only by its influence on the accumulation of capital, 151. Wages not determined by discounted product of labor because there is no rate of discount established independently of level of wages, I53. Criticism of productivity theory on ground that specific product of labor is not ascertainable, 155 .

Conclusion - General level of wages is determined by size of wages fund and the supply price of different quantities of labor, 157 .

\section{Chapter IX. Conclusion.}

The two stages in our analysis of the problem of distribution, 159. Criticism of the concept of capital as including land, I6o. Criticism of the "law of three rents," I6o. Summary of conclusions reached, I63. The return to the classical school of economists, I64. Unfortunate tendencies of modern economic theorizing: (I) Excessive rationalism, 166. (2) Confusion of problem of distribution with that of value, 167 . 


\section{PROFIT AND WAGES}

CHAPTER I

INTRODUCTION

In the meaning usual to economic literature, distribution is division into parts and the apportionment of the parts to those who share in the division. Now it is the distribution of income rather than of wealth with which we are here concerned. Income is wealth just produced or come into existence. It should be thought of as a stream and measured by its volume per unit of time. Taking the collective view essential to the science of economics the problem becomes that of the division of the total income or produce of human industry. We are to explain how the flow of goods from mine and farm and factory spreads and divides into streams of private income, - into the rent, profit, and interest, for instance, which fall to the well-to-do, or the wages with which the poor must be content.

As the ultimate significance of these streams of goods is in the uses made of them, one might regard income as consisting of the feelings of the consumer of goods rather than of the goods themselves. But such a conception of income would not serve the purposes of the present inquiry. "Psychic income" is too remote from 
the problems with which a study of distribution must begin. The amount of utility derived from equal quantities of any commodity varies widely as between different consumers and even between different times and conditions for the same consumer. The final determination of psychic incomes, therefore, lies in the process of consumption. It comes at a later stage than that of distribution.*

Income is measurable only as a rate, as amount per unit of time. The total of wealth, on the other hand, cannot be measured otherwise than by taking the quantity existing at a point of time. As such it would include the income of the moment but also the wealth which has arisen or come in at previous times and which still remains unconsumed and undestroyed. When referring to income, the term distribution evidently denotes a process. When applied to wealth, however, it means the result or outcome of a process of distribution, or of a series of such processes. The method of investigation must differ according as the object of inquiry is the process or the result. To picture the result, the distribution of wealth at any point of time, the only satisfactory method would be the statistical. If complete data were available, the statistician could tell us how many rich men there are and what is their wealth, and how

\footnotetext{
*A very satisfactory discussion of income thought of as a stream of goods can be found in Lexis, Allgemeine Volkswirtschaftslehre, p. $137 \mathrm{ff}$.
} 
many poor there are and what is the depth of their poverty. The explanation of how this distribution came about would constitute an historical problem. It is not, however, the object of the present essay to describe and explain the distribution of an existing stock of wealth. Our problem is the complicated process of parcelling out the newly produced wealth or income of society. In the analysis of such a process statistics and history can give little aid. At least in the initial, and most difficult stages, of the inquiry, the method of "theory" alone is of service.

This is the method of mental experiment with different lines of approach to the problem,the exploitation of different facts and ideas as tentative premises. The forces of our industrial system are so involved that no conception of its operation could be reached by any attempt to describe its details. In fact the more photographic and concrete the picture presented to the mind, the more confusing and difficult the problem becomes. The only feasible procedure, therefore, is to seek for essential facts and to reason from these, while deliberately excluding from view a mass of complicating phenomena. Intellectually portable and manageable results are won by selection only. Complications must be eliminated, or, in other words, hypothetical assumptions must be made. Economic theory differs from other sciences only in the degree of its hypothetical character. 
But for use in practical affairs, or to satisfy a mental craving for a more concrete picture of the world, our first simplified, hypothetical, general theory may be subjected to a series of qualifications by bringing in one by one the complicating conditions which had been excluded at the beginning. Thus a series of propositions may be reached which, descending into ever greater detail, lead us by successive approximations* to a closer view of things as they are. How closely we desire to approximate the confusing reality of our industrial life, or at the other extreme, how far we are willing to carry the process of abstraction to gain a general view, depends largely on our mental constitution. It is not altogether flippant to call it a matter of taste. In the end, however, the use we intend to make of our theories may decide to what degree of abstraction from or approximation to the complexities of the actual world we may safely proceed.

*The idea of "successive approximations," a metaphor derived from physics and mathematics, has perhaps received its vogue especially from Pareto (Cours d'économie politique, p. 16 ff.). Graziani (Instituzioni di economia politica, p. 45) attributes the use of the term especially to Pareto and Barone but says that the method itself goes back to the classical writers such as Smith, Ricardo, and the two Mills. It has probably been used more or less deliberately by many writers. The opening paragraph of the third volume of Das Kapital, for instance, shows Marx making conscious use of this method. The mention of Marx suggests the dangers and difficulties of beginning with assumptions too remote from reality. A recent instance of a start too remote from reality, in the present writer's opinion, is that made by Schumpeter (Theorie der wirtschaftlichen Entwicklung). 
It follows from what has just been said that the general theory of the distribution of income aimed at in the following pages must submit to certain limitations. To state some of these, (I) it must confine itself to what may be called the primary process of distribution, the dividing up of the product of industry among the parties immediately connected with the productive process. In other words, our problem is that of wages, interest, profit, and rent. How secondary incomes are derived from these primary shares through gift, theft, begging or taxation, need not concern us. Profits or other incomes from business operations which are not productive or whose relation to production is remote and uncertain, must also be omitted from consideration. Various "pecuniary" employments of capital, as Veblen would call them, - speculative manipulations, for instance, - for all their spectacular interest and disturbing significance, must be excluded. To get a clear view of the fundamental factors, our study must stick closely to the process of production and to those classes which draw their living immediately from that process. (2) Our study must assume the prevalence of competition. At a time of widespread apprehension of the growing power of large aggregations of capital, this assumption may appear to lead to conclusions somewhat too remotely connected with contemporary conditions. However the extent of the monopoly exercised by those 
to whom popular opinion attributes this power, is somewhat in doubt and certainly their power is not absolute. The mixture of competition and monopoly in the industrial life of today cannot be understood unless we have a clear conception of the workings of a competitive system. For the purposes of our theory it will be well, therefore, to set aside monopoly as a disturbing factor acting upon a fundamentally competitive order. In other words we reach a "first approximation" by assuming a competitive system. (3) Another limitation to which our theorizing must submit is in the historical range of its application. It is confined to present conditions, to the "system of industrial liberty," to "capitalism." Starting from facts and conditions of the present, it may not assume universal validity for its conclusions. On the other hand it is under no necessity of accounting for the origin and evolution of economic institutions which our industrial system has inherited from the past. It may take their existence for granted, asking only how they affect the quantity of income going to the different "shares in distribution."

The foregoing limitations are observed throughout this book. Other assumptions will be made from time to time to save the argument from unnecessary complication. Although these are not always explicitly mentioned, we trust they will be reasonably obvious to the reader and will be such as experience has shown 
to be necessary to the operations of economic theory. The results reached by the method pursued are necessarily propositions of an abstract character. To the type of mind that hungers for graphic and abundant detail they may appear very unsatisfactory. But our present aim is an analysis of the industrial world, not photography, and so no other course lies open.

To find the starting points for an analysis of the distributive process it will be prudent to examine the results of the mental experimentation of leading thinkers in this field. The stock of facts and ideas with which theory operates is selected from a complex reality largely in the form of general impressions of what may prove significant. A review of the impressions of able theorists as to what elements enter into the determination of the shares in distribution, and of the failures and successes of the different theories set forth, is the only sure precaution against making a false start. Our work then must be largely critical. That to save time the discussion is restricted to theories which still have some standing in scientific controversy will, we trust, commend itself to the approval of those competent in economic studies. But before entering into the necessarily technical, and perhaps confusing, detail of a critical study, it may be well for the sake of perspective to offer the reader a general 
sketch of the field we are to enter. This is the purpose of the remaining pages of this chapter.

The classical economists represented the national product as divided among landowners, capitalists, and laborers - three rather distinct classes in the social life of the England of their day. A fortunate tradition for the theory of distribution was thus established by an historical accident of time and place. Had the owners of capital and those of land been merged as completely as they were in some countries and as they are in the England of the present time, economic theorists might have failed to isolate the share in distribution that falls to the landowner as such. A part, at least, of what goes under the popular term of rent of land, has important characteristics which distinguish it from the income of capital. As will soon appear, it is a differential gain of a rather permanent character. Not to recognize this would seriously distort our picture of the distributive process. In the writer's opinion, it was fortunate also that economists did not at once make and emphasize the distinction between capitalist and entrepreneur, which later came into fashion. The capitalist is lender and investor only of capital, the entrepreneur user of it. To an increasing degree the entrepreneur is coming to be not an individual, but a group of men, a corporation. It will be convenient, however, throughout most of our discussion to think of 
him as an individual business manager. So conceived, he is the one controlling and directing the process of the production of wealth. The products are his until he sells them. If they are unsaleable, the loss is his. He may be capitalist and landowner besides being entrepreneur. Indeed, he usually owns some capital. Out of the process of buying, borrowing, and hiring for his business, and the sale of the products, he gets his profit. To the landowner he pays rent, to the capitalist interest, to the laborer wages. The problem for the theory of distribution is, what determines the amount of each of these shares in distribution - rent, interest, wages, and the entrepreneur's profit.

Confusion enters into this controversial matter at the very outset, through the failure to agree upon some distinct concept of capital. What is this thing whose ownership gives the power to get an income without labor, or in other words, to levy on the labor of others? Popular terminology is indefinite and shifting. One meaning suggested by it, that of capital as a sum of money is obviously inadequate for our inquiry. Even if it were permissible either to overlook bank credit or to regard it as a kind of money, this popular concept would be too superficial. It is what is bought with the money by the managers of productive enterprises that makes it effective in securing an income and, which, therefore, constitutes the true capital. It will be advantageous at least 
in our first approximate formulation of the theory of distribution, to forget the existence of money and to think of commodities and services as exchanged by barter, though with a celerity and ease not possible to that crude method of exchange.

Passing from popular usage to that of the more scientific literature of economics, we meet a discouraging diversity of opinion. In general, however, there are two tendencies. One is to regard capital as a sum of value, the other as consisting of concrete goods of some kind. To consider capital as value (or as a sum of prices) instead of using value or price merely to measure a quantum of capital, gives a concept useful only to one theory of interest, the time-preference theory, and not acceptable, therefore, unless that theory can be accepted.* Of course the concept is also useful to the bookkeeping or accounting of private and individual economics (Privatwirtschaft). Our aim, however, is not to describe the individual's method of measuring his gains, but to explain the source and amount of income that goes to the owners of capital as a class. *Professor Clark employs a concept of this kind in connection
with a productivity theory. Obviously, however, it is the
concrete "capital goods," which he distinguishes from the
fund of capital or capital proper, which really aid production
and constitute the basis of the capitalist's income, not the
abstract fund or collective value of these goods. See remarks
by Carver in Quarterly Journal of Economics, May, I907.
See also the trenchant criticism by Bohm-Bawerk ibid.,
November, I906, and February, I907, and by Veblen ibid.,
February, I908. 
Of definitions of capital as concrete goods there is a considerable variety but two may be taken as dividing between them a large part of the usage of economic literature - one, that of capital as consisting of "intermediate goods" or goods prodiced to be used in further production; the other, as subsistence maintaining labor in the long process of production, and advanced to the laborers out of past product by the capitalist class. Which of these is to be preferred can be decided only when we inquire what each leads to when used as a basis for a theory of interest. Some reasons will be given at this point for choosing the view of capital as subsistence advanced to the laborers. The chief purpose of these remarks, however, is not to dispose definitively of the question of the proper definition of capital, but to give the reader the background of a general picture of the production and distribution of wealth.

If capitalists as a class enjoy a peculiar income, that income must in some way be traced to the peculiar contribution made to the productive process by capitalists as a class. To this contribution it would seem appropriate to give the name capital if that trouble-breeding term is to be used at all.* Now what capitalists

*Something might be said in favor of dropping the term altogether from economic theory because of the confusion it has always caused. The dreary debate about its proper meaning has had the advantage of establishing in our terminology a number of convenient names for proposed claimants for the title of capital, e. g., intermediate goods, producers' goods, 
as a class contribute is the subsistence of the laborer or wages (that is real wages). This appears when we consider the entire process of the production of any consumable commodity, viewing it as beginning with the first labor employed to make any instrument or material used in the course of the long process. Production is then seen to be simply the use of labor power on the physical world. The process of making any commodity may be, and usually is, divided into different stages, controlled by different entrepreneurs. The latter contribute the labor of scheming and directing, but the capitalists, or the entrepreneurs in so far as they are capitalists, contribute nothing but the wages paid to the laborers.* This is the one investment of capitalists as a class with reference to productive enterprise. The "capital goods" such as machines, raw material, etc., which appear in the productive process, are bought by one capitalist or entrepreneur from another. The purchase and sale of these products or intermediate goods, however, is a purely intraclass affair. Such purchases and sales are a

consumers' goods, durable goods. The use of these terms in place of the ambiguous word capital would clarify many economic discussions.

* Our reason for not mentioning the rent of land among the payments made by the capitalist will soon appear (page I $5 \mathrm{ff}$.). Taxes may also be disregarded. We may think of them as paid out of income and, in any case, as having no necessary direct relation to the process of producing and distributing wealth. 
means of dividing up between different capitalists the capital investment necessary in the long process of producing any consumable commodity. The buyer of a machine for instance, pays the seller the wages the latter had paid in having the machine made. As the price of the machine, however, also includes interest and profit to the seller, the purchase and sale of such "intermediate goods" also appears as means of dividing up the profits and gains of capital of the entire productive process. But these transactions within the class of capital owners constitute no part of the necessary contribution of the capitalist class to the process of production. The necessary contribution of this class, the investment from which it derives its income, the mysterious thing called capital, consists of the subsistence or "real wages" given the laborer. For the theory of distribution at least, this seems the most fruitful conception of capital.

And now we return to the question asked a few pages back as to what determines the amount of each share in distribution - of rent, interest, profit, and wages. In the attempt to give a preliminary sketch of the questions at issue, we may start with an idea which has come very near to having gained universal acceptance among economists, and make it the background for a formulation of the principal contending theories. This idea is that of a distinction between differential and marginal income. The 
productive result of the investments made by capitalists and entrepreneurs varies widely. Any return in excess of the lowest or marginal rate of productivity is a differential gain, and may take the form either of rent of land, or of differential profit. The most permanent differences in productivity are inherent in the quality and location of the land which is used. Less stable differences may be traced to the differing abilities and luck of the entrepreneurs.

As the capital of the world increases, entrepreneurs proceed to less and less productive investments - assuming that they first took advantage of the best opportunities. The course of investment is from more to less productive lands and locations, stopping at successive "extensive margins," and also from more to less productive investments on the same land, according to the "law of diminishing returns," making successive stops at "intensive margins."* On the assumption of perfect mobility of capital, a given total of capital will be so distributed in its investment as to establish a uniformly productive margin along

*The law of diminishing returns from land will hold, that is there will be an increase of total product but a diminished product per unit of investment, if the additional "capital" invested takes the form of, or results in, an increased application of either labor or capital goods to the land. As will appear later, it is possible that an increased supply of capital may bring about nothing but an increase in the rate of wages. In that case, of course, there is no increase of total or decrease of marginal product. The relative shares received by capital and labor will be changed, but there will be no change in the differential gains. 
both the extensive and intensive frontier. Additions to the supply of capital can then be invested at the margin only, and get only the marginal rate of return - unless they can displace capital at other points. The competition of this new capital with the older supplies which it is capable of displacing, tends to make the marginal rate the rate of return for all capital, by giving the landowner the power to demand all in excess of this (except the "ability rent" of the superior entrepreneur) as a rent.* At the outset, of course, the entrepreneur receives the entire product, but the destination of all the differential gain, the surplus over the marginal rate of return, is apparent.

We may thus view the problem of distribution as being, at the first stage, a question between

*The rate of "productivity" of capital at the margin would vary accordingly to the ability of the entrepreneurs managing it. A marginal rate, therefore, if it is to be something definite, implies a marginal managerial ability. The amount of capital (and consequent size of business) controlled by different entrepreneurs tends to vary according to their ability and energy, the least competent of the entrepreneurs able to maintain themselves against competition, the marginal entrepreneurs, controlling the smallest business units. This on the assumption, very far indeed from being fully justified by the reality, that the control of capital is distributed according to ability and not by accident and favor. Because of the advantages of large scale production, those able to manage large amounts of capital will get a higher rate of return than the marginal entrepreneur, a differential profit, even for their marginal investments. The marginal rate pays only interest and "wages of management" to capitalist and entrepreneur, but the abler entrepreneurs get more than this rate. Even under static conditions, therefore, there is a differential profit graded roughly according to the ability of the entrepreneur. Under dynamic conditions, there are also the temporary gains that come to the alert, progressive, and lucky ones. 
entrepreneur and landowner. Whatever the productive forces applied to the land, they represent capital investment to the entrepreneur. When they yield a surplus above the marginal rate, this becomes either the rent of the landowner or the differential profit of the entrepreneur. But this division between differential and marginal income is not the whole of the distribution to be made. The entrepreneur has also to deal with the laborer and the question then becomes that of dividing marginal income, the product remaining after the subtraction of the differential gains. Here we reach the questions most in controversy. The fact of differential gains is pretty well acknowledged, however much economists may disagree in regard to its different aspects. But on the problem of the division of the "marginal product" between capitalist and entrepreneur, on the one hand, and the laborer, on the other, there are the most persistent and irreconcilable differences of opinion. A discussion of the theory of distribution inevitably must deal chiefly with the controversies over the character of the apportionment of the marginal product between capital and labor.

A diagram may be used to show the relation between differential and marginal incomes. Let the figure $C A E D$ represent the total product of industry. Distance from line $A E$ measures productivity and distance along $A E$ the quantity of capital invested. $D E$ indicates productivity 
at the margin, and $C B D$ the total of differential gains (rent and differential profit). The controversial problem for the theory of distribution is that of accounting for the division of $A B D E$ between labor and capital.*

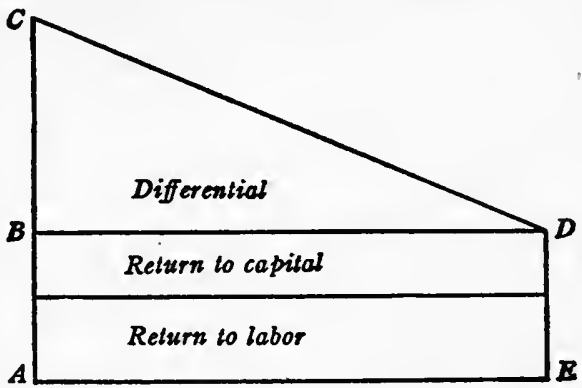

Holding throughout the point of view gained by setting aside rent and some profits as differential and concentrating our attention on the division of the marginal product and the rates

*The diagram is constructed with reference to illustrating the quantitative aspects of the division of the total product rather than the source of each share. It would be misleading if it suggested that labor and capital get their return from the same monthly or annual product. If capital gets its return from current product, then wages must be thought as paid out of earlier product. The rectangle $A B D E$ should really be interpreted as that part of the gross income of the entrepreneur left after deducting rent and differential profit, and the portion marked "return to labor" as the equivalent of the wages which have been paid.

For the sake of a simplified statement no mention is made above of non-differential profits, or what are sometimes regarded as "wages of management." Some writers would merge them with the return to capital as part of the "profit of capital" (Kapitalgewinn); others would merge them with wages as payment for labor. Reasons for giving our preference to the former alternative will appear later. 
of interest and wages thus established, we may mention briefly some of the principal attempts to explain the division of product between capital and labor.

One method of explaining the existing division of $A B D E$ is to find a factor determining one of the two shares independently of the other and of the amount to be divided. This leaves the recipient of the other a "residual claimant." Ricardo, for instance, describes the share going to labor as determined by the cost of the laborer's subsistence according to some more or less fixed standard of living. The remainder of the marginal product would then constitute "profit of capital." Or, on the other hand, wages may be made to appear a residual income by representing the return to capital as determined by some subjective factor such as cost of abstinence or waiting, or by the degree of preference for present over future possession. A favorite variant of the theory appears when wages are spoken of as the discounted marginal product, the rate of discount being set by the "rate of time-preference."

Another method of explaining the division of the marginal product is to seek for an independent explanation for each of the two shares. Thus the theory of specific productivity declares that capital and labor receive each its specific product.

Another method rests on a denial of the possibility of an independent explanation for 
either share and declares the existing division to be simply the outcome of a struggle between capital and labor. This is the view suggested by the frequent reference of German writers to Machtverhältnisse, to relative power, as determining distribution, and by the somewhat more definite "bargain theory" of wages set forth by Davidson.*

In seeking to account for the division of product between capital and labor, we appear to be restricted in our choice to one of the three methods just indicated. We must find (I) an independent explanation for either wages or the gains of capital, in which case we may account for the other share as residual. If that cannot be done we must either find (2) an independent explanation for wages and also such an explanation for interest, or (3) we must regard the division of product between capital and labor as the outcome of a tug of war.

*The Bargain Theory of Wages. 


\section{CHAPTER II}

\section{BÖHM-BAWERK'S THEORY OF INTEREST}

It is a not uncommon practice to treat of one of the shares in distribution, of wages, for instance, or interest, or rent, without showing its relation to the remaining shares. A satisfactory theory of any one, however, implies some particular view in regard to the others. Every consistent thinker on these subjects holds a definite theory of distribution as a whole. He cannot rest satisfied with disconnected theories of wages, interest, profit, and rent. But, however desirable it might appear to consider theories of the entire process of distribution, rather than theories of particular incomes, a critical study such as has been proposed above, must accomodate itself to the disjointed character of economic discussion. A beginning must be made with some one of the so-called shares, and for various reasons the theory of interest will best serve as an introduction to the problem before us.

Now a strategic point at which to begin is given by the agio theory of Böhm-Bawerk. It is a highly developed and individual doctrine, based on a searching criticism of other theories. Stated with great clearness and amply elaborated, it is free from the obscurities of much of the older speculation on this subject. It 
will be desirable, therefore, in the case of this eminent writer to depart from the rule, adopted in most of the following pages, of considering general types and schools of thought rather than the formulations of particular theorists.

The fundamental concept of Böhm-Bawerk's theory is a preference for present goods over an equal quantity of future goods of the same kind. Because of this preference, he holds, interest is paid as a premium for present goods given in exchange for future goods; or expressed differently, interest is a discount to which future goods are subject when exchanged for present. Now undoubtedly a preference of this kind exists, and may manifest itself when there is occasion for comparing present and future sums of money, or commodities readily exchanged for money. This preference, however, is obviously due, in large part, if not wholly, to the possibility of obtaining interest from the investment of money. It is a result of the existence of the institution of interest rather than a possible factor in bringing about its existence. The problem raised by BöhmBawerk's theory therefore becomes the highly hypothetical one of whether, if there were no interest payment to be expected - if, for instance, interest were prohibited and the prohibition enforced, - there would still be a preference for present goods, (or money as a means of purchasing goods) over future goods (or money). And Böhm-Bawerk adds to the 
hypothetical character of the problem by eliminating the effect of any uncertainty in regard to future goods, such uncertainty not being necessary to a preference for present goods though adding to the discount of future goods.* If a preference for present over future possession, existing independently of the possibility of obtaining interest and not arising from any uncertainty or risk attaching to the future goods, could be proved, this preference being felt by a considerable number of persons and to a degree sufficient to be of significance and to lend probability to a theory based upon it, then Böhm-Bawerk's theory would not, indeed, be fully established, but would have a clear title to further consideration. For a complete demonstration of the truth of the theory, it would be necessary to show that such a preference for present goods could and does alone account both for the existence of interest and its amount.**

As proof of the existence and operation of the preference for present goods to which he attributes the appearance of interest on capital, Böhm-Bawerk gives three "causes" of such

\footnotetext{
*"I repeat that the element of uncertainty, which is the cause of a lesser value being put upon particular classes of future goods, has no causal connection with the phenomenon of interest. The lesser valuation which is its effect is a special one, and extends to one class of future goods only, and there it bears the character of a deduction as premium for risk." Positive Theory of Capital, p. 247.
}

**Except in so far as the amoun $t$ is affected by the element of risk. 
preference: (I) differences in relative provision for present and future wants, typical cases being that of immediate distress and that of prospects of increased wealth in the future, (2) the underestimate of future advantages and future goods due to want of imagination, defect in will, and the uncertainty of life, and (3) the "technical superiority" of present goods. The third of these causes of preference, being based on a technical fact in the field of production, is evidently of a different nature from the other two. It is also the one which has been most called into question, and, therefore, may properly be the first to be subjected to a critical examination. The "technical superiority of present goods," according to BöhmBawerk, rests on the greater productivity of a long process of production compared with any shorter process using the same quantum of productive powers. In this statement the process of production of any commodity must be understood as including not only every step in making and marketing the commodity in question, but all preliminary steps, such as extracting and refining the raw material, making and transporting necessary instruments of production, et cetera. The longer process, therefore, is the one with the relatively larger amount of the results of previous labor employed in the later stages. In the older and more familiar phrase, it is the one with the larger "investment 
of capital."* The proposition that an extension of the process of production over a longer period results in an increase of product per unit of investment, is at bottom only the familiar assertion of the productive advantage of increasing capital equipment. BöhmBawerk's novel formulation of this, however, led to some controversy. In his Strittige Fragen and in the third edition of the Positive Theorie des Kapitales, he has no difficulty in disposing of most of the objections made to the proposition in question. However, it appears that a continued lengthening of the production period, beyond a certain point, results, not in an increasing, but in a decreasing rate of return.** With

*The amount of capital invested does not, however, vary exactly with the length of the productive process. See third edition of the Positive Theorie des Kapitales (Exkurs V).

**To measure the length of the production period of any commodity, we must take, according to Böhm-Bawerk (Positive Theory, page 88), not the "absolute" duration, the time elapsing between the first step in the process and the last, but its average. The latter is calculated by first multiplying each productive unit invested (of labor and of "uses of land") by the number of years from the time of investment to the completion of the consumable commodity, then adding together these arithmetical products and dividing by the number of units invested. Böhm-Bawerk, in his explanation, leaves out "for the sake of simplification," the co-operating "uses of land." In this we may follow him with a clear conscience if we reflect that, on the margin of land, there is no special outlay for rent and hence no investment, other than what is paid for labor, entering into the calculations of the entrepreneur. Now let us assume the total of labor employed in making a given commodity to remain unchanged, the length of the production period being increased by increasing the proportion of this labor invested in the earlier stages of the productive process. The result would be an increasing proportion of equipment to labor at 
this qualification we may accept Böhm-Bawerk's proposition in regard to the relative productivity of different production periods.

Now can it be shown that the greater productivity of the longer processes is a reason for preferring present to future goods or earlier to later ones? The only way to do this would be to show that, of productive processes to be begun at different times, those with an earlier start are the longer and consequently more productive ones, or, in other words, that postponing a process of production means shortening it and thereby diminishing its productivity. But a shortening of postponed enterprises at a sacrifice of productive efficiency would be without motive, unless it be permissible to assume that whether the start be early or late, the date when the product is completed is the same. It is as if we had to decide that whether we begin in 1914 or 1915 or 1916 , the product was to be finished on, but neither before nor

the later stages. The entire product would pass through the hands of the laborers at the latest stages and their output, therefore, would measure the productivity of the whole process. After the increase of the production period has brought about the maximum amount of equipment each of these laborers could use effectively, and the maximum he could produce, further extensions of the process would result, at best, in no increase and, perhaps, in a decrease of the product per laborer. At the same time the number of these laborers is diminished as more of them are shifted to the earlier stages. The outcome would be a decline in the total product, and as the total of labor invested was assumed to remain unchanged, a corresponding decline in the amount of product per unit of labor invested. A further extension of the production period would be to no one's interest. 
after, a definite date in r9r7. Obviously such an assumption respecting the time when productive processes must yield their fruit, is without warrant save as applied to exceptional cases. Contracts for completing buildings or furnishing supplies within a certain time (not usually on a definite date) are common enough, but being made under conditions which allow practically no choice as to the time of beginning work, are not relevant to our problem. The only occasions for comparing productive processes begun at different times, but aiming at completion on the same date, would be those created by expected events or opportunities of a temporary and unusual character, by what German writers would call a Konjunktur. Such would be the occurrence of an international exposition, the opening of a canal or of a new railway, the outbreak of a war, etc. But most economists would agree that there is a difference between a Konjunkturgewinn, the gains of a special and temporary opportunity, and interest on capital, and that the latter income must be derived from some more constant and regular source. As regards the great majority of productive operations there is no occasion for comparing the results of processes begun at different times and no necessity for shortening postponed processes because of any need for completing them on a given date. It is, therefore, impossible to prove a purely technical or productive advantage in present over future 
possession of the means of starting a productive enterprise. The only conceivable conditions under which such a "technical superiority of present goods" could arise are too exceptional and restricted to form the basis of a theory of interest.

The greater productivity of the longer process, of the larger investment of capital, under certain conditions and within certain limits, is a fact and one of some significance to the theory of interest. Böhm-Bawerk presents it as the most important of those which must enter into the explanation of the income of the capitalist. In the writer's opinion he does not overestimate the relative importance of the technical factor. It is, in truth, the only one of those given by him that constitutes an essential element of a general theory of interest. But he has not given the right name to the fact which he is using. It is not a superiority of present goods, i. e., a technical advantage of present over future possession, but the productive advantage of having a certain capital over that of having less capital or none at all. It may, perhaps, form the basis for a kind of productivity theory, but it cannot be fitted into a pure agio theory. In short, it does not constitute a direct and immediate cause of preference for present over future goods.

In a more remote way, however, it may be the cause of such preference. If we grant that the greater productivity of the longer 
process is one of the factors causing the existence of interest, and that the possibility of deriving interest from money, or goods convertible into money, is a good reason for wishing to have said goods or money now rather than later, we must conclude that the superior productivity of long processes is indeed a ground of preference for present goods. But such preference is a result, and not as Böhm-Bawerk would have it, a cause of the existence of interest on capital. In regard to the "technical factor" we may conclude, therefore, that its contribution to the creation or maintenance of interest on capital cannot be of the same nature as that of Böhm-Bawerk's other "causes of preference for present goods." Böhm-Bawerk's bias in favor of unitary theory, or, as Landry calls it, his "fear of eclecticism," has apparently led him to make a desperate attempt to demonstrate the technical factor to be a direct cause of preference for present goods, parallel in its action with the other two factors. Such an attempt must necessarily fail and the three "causes" cannot be brought together under one head. If all three are to be retained for the explanation of interest, a theory resting on time-preference alone, a pure agio theory, is an impossibility. 


\section{CHAPTER III}

\section{THE TIME-PREFERENCE THEORY}

The conclusion reached in the preceding chapter that Böhm-Bawerk's technical factor will not fit into a pure agio theory, is that held by apparently the great majority of economists. With some qualifications, perhaps, this factor may form the basis, of a kind of productivity theory. It cannot be made to appear as a direct cause of a preference for having goods at one point of time, rather than at another. But now arises the question as to whether a satisfactory theory may be reached by eliminating the technical factor from consideration and operating with the other two causes of preference, those which a careless but convenient usage permits us to call the subjective factors. This has been the method of several recent writers* and may be regarded as a very consistent development of the tendency to reduce economics to a theory of valuation. It merits a careful examination. But instead of assuming the active existence of the subjective factors and inquiring merely into their sufficiency to give a complete theory, it is necessary to approach the problem in a more fundamentally sceptical attitude and to ask whether these

*Especially Professors Fetter and Irving Fisher. 
factors actually play any part whatever in bringing about the existence of interest or in regulating its amount and percentual rate.

Let us then take a glance at the two nontechnical or subjective causes of preference mentioned by Böhm-Bawerk. In regard to the second of these, the underestimate of future advantages, it may be admitted that lack of imagination, weakness of will in the face of the temptations of present enjoyment, the uncertainty of human life and, perhaps, other circumstances, may bring about a tendency to over-rate present compared with future goods. This, of course, is acknowledging the existence of uneconomic tendencies. It is admitting the irrational, the uneconomic man as a disturbing force into the beautifully ordered, rational world of economic theory. Yet if actual mankind is so irrationally disposed, why not recognize the fact in economic study? Doubts regarding the importance of the factor, arise, however, when we ask whether persons whose preference for present goods rests on such weakly human grounds are likely to be in a position to offer sufficient security for the fulfillment of contracts, to be enabled to enter into an exchange of future for present goods. The important question in this connection, in fact the only relevant question, is not whether such preference for present goods might or does 
exist, but whether it plays a part in the business facts that give rise to interest on loans and investments.

And the same remark applies to Böhm-Bawerk's first cause of preference for present possession. We may grant that an anticipated relatively more abundant provision for future wants is an experience entering into the lives of a considerable number of persons. That is, they have such anticipations, whether or not these lead to any conscious preference for present goods or to actual offers of a premium for present possession. That it is the experience of the majority may perhaps be doubted and it is not impossible that conditions may be reversed and the present be the relatively better provided for. In that case it would be rational to feel a preference for future over present goods. This possibility is hardly referred to by BöhmBawerk, whose thinking is directed toward finding the explanation of interest in what he considers the almost universal human attitude of a preference for goods in the present.* Of course those who prefer future goods to present goods, might be represented along with those having only a slight preference for present goods, as parties to an exchange with those feeling a relatively strong preference for goods in the present. But, on the whole, the agio theory

*However, he holds that for most capitalists this preference rests on the "technical superiority" of present goods and that the first two grounds of preference, the subjective ones, are of no effect. See $3 \mathrm{~d}$ ed. of Positive Theorie, p. $52 \mathrm{I}$. 
requires that preference for present goods be a more urgent and wide spread factor than the preference for future goods. If such should not be the case, that is if those preferring present goods could always find persons with a preference for future goods, an exchange might be arranged, advantageous to both parties, in which no interest or discount need appear. Now does Böhm-Bawerk's first "cause," the factor of a difference between provision for present and for future wants, take a shape such as to create a very general preference for goods in the present? It appears, at least, doubtful. Those whose income is gained by their own labor, may in youth have before them the prospect of earning power increasing with age and experience; but such increase of income may be accompanied by the increased expenses of a growing family, and will be followed by a decline of earning power with advancing years. Those, on the other hand, whose income is derived from investments, may have reason for expecting a constant growth of income from their increasing accumulation of savings. Their relative underestimate of future goods would however be due to the existence of income on capital. To represent it as a cause of interest would obviously be reasoning in a circle.

Böhm-Bawerk's first two grounds of preference for present goods, the subjective factors, appear, therefore, to offer no very secure foundation to a theory of interest. In fact, Böhm- 
Bawerk himself virtually surrenders them except in his theory of the "consumption loan." The exponents of the pure agio theory, however, have put forward no other grounds of such preference. They rest their case entirely on something for which no adequate explanation has been given.

But for the sake of argument let us grant that there may be good reasons for wishing to have goods at one time rather than at another, and that, on most occasions the preference would be for goods in the present. For any preference, one way or the other, between goods to be got at different points of time, we may use the convenient term time-preference. ${ }^{*}$ When such preferences are presented as growing out of fairly definite, quantitative comparisons, we evidently have an extension or development of the Austrian theory of value; the "economic man" being represented as comparing the relative utilities not only of different goods in the present and immediate future, but of the prospective goods of years to come. Interest becomes a problem in "subjective value." For let us note, that when Böhm-Bawerk's technical factor is eliminated from consideration, the comparison between goods, or between the

\footnotetext{
*This term is used by Professor Irving Fisher but in a more restricted sense, as a preference for present over future goods. (The Rate of Interest, p. 88 and elsewhere.) In Professor Fetter's Economics the term time-value is used in the sense in which time-preference is employed here.
} 
"incomes" from goods coming at different points of time, is made by the consumer and between consumable goods only.

This may arouse doubts in regard to the applicability of the theory to those facts in which the consensus of opinion among economists looks for the chief source of interest. What part do the factors it emphasizes play in real business? When capital goods or profitable opportunities are valued, it is on the basis of expected pecuniary returns, of that interest whose nature and amount the theory in question seeks to explain, of the objective facts of the industrial world rather than of the subjective states of the consumer. How to bridge the gulf between the subjective, the consumer's estimates of goods, and the objective facts of industry, constitutes a serious problem for those who would base interest on timepreference alone.

What are the actual mental states of the men who put their capital into business and get an income in the shape of interest? The professorial imagination has displayed great ingenuity in showing how comparisons between present and future utilities might be made and time-values noted. But such mental exercises are of no importance unless time-preference is a psychic state that actually enters into the transactions out of which interest grows; unless it plays a part in borrowing, lending, and investing. The only relevant question, there- 
fore, is not that as to possible reasons for having a time-preference, or as to the possibility of the occurrence of this state of mind, but as to whether such a preference or valuation is an essential part of the psychology of business. What really goes on in the investor's mind? In the borrower's and in the lender's mind?

That economists have been so ready to accept time-preference as a factor affecting investment is possibly due to an uncritical identification of it with the older concept of abstinence; the transition from the older to the more recent conception being facilitated by the use of such terms as postponement, prospectiveness, and waiting. In the idea of an exchange of present against future goods in which timepreference may play a part, we have, however, something essentially different from the thought of the older abstinence theorists, and a view of things less likely to recommend itself to an unsophisticated understanding of what takes place in this world. By the older writers abstinence was taken to mean abstaining from consumption in order to accumulate and invest capital, and the continuance of the abstention in order to maintain the capital accumulated. It was regarded as involving some deprivation or "cost" and, therefore, requiring some compensation. Interest was the necessary "reward of abstinence." This view, however, did not of necessity imply that in the exercise of abstinence there was a postponement of consumption, 
i. e., that the capital sum saved and maintained by abstinence, was ever to be consumed. Such an idea, however, is suggested by Böhm-Bawerk's exchange of present for future goods. It implies in the capitalist's mind a comparison of two quantities of consumable goods; of a present quantity on the one hand, with an equal future quantity of goods, in addition to the interest, on the other.

This manner of presenting the calculations of investors is an obvious departure from the facts, a misrepresentation of the psychology of investment. Very few investors ever contemplate consuming what they call their capital. Investment to them does not mean postponing the consumption of the equivalent of what they have saved. In fact, whatever hardship or cost may have been involved in saving a given capital, it would probably appear a more heartrending thing to be obliged to consume the capital that has been saved. The capital sum, therefore, does not enter into both terms of the comparison between present and future goods. What the investor does is to compare the present or early consumption of, let us say, one thousand dollars worth of goods once and for all, with the later consumption of a permanent, annual income of fifty dollars worth of goods, obtainable without labor. There is a comparison, indeed, of consumable goods, or if you will, of "psychic income" or utilities of goods; but it is of goods or income appearing 
under very different conditions. The one thousand dollars if spent for purposes of consumption are gone. Another accumulation of one thousand dollars can be obtained perhaps only by performing labor. The fifty dollars received as interest, may be spent, but an equivalent sum will come again, year after year, and without exacting labor from the investor. A relatively large temporary satisfaction of wants may be given up when one thousand dollars is saved; a permanent, unlaborious recurrence of a much smaller sum is gained. The permanent character of interest income and the fact that it comes without labor on the part of the recipient, are to the capitalist the significant characteristics of the "future goods" he purchases by means of his "present goods." These real or apparent characteristics a theory of interest must account for. Their existence granted, we can see why men will make sacrifices to obtain interest.

In the case of the active entrepreneur, as distinguished from the capitalist-lender, the calculations of an investment are slightly different, but equally unfavorable to the timepreference concept. The entrepreneur also hopes to get a permanent income as a percentual rate of his thousand dollars; but he looks for a higher rate than the capitalist, for what following the usage of the classical economists, we may call "profits of capital." When receiving the higher rate he does not expect entirely to 
avoid risk and labor. The most important aspect of investment to him is the fact that it represents business opportunity. Neither capitalist, nor entrepreneur, however, let a future capital sum enter into comparison with present goods. They are not conscious of making any such exchange of present against future goods as is suggested by the language of BöhmBawerk and his followers.

It is evident that the purposes and calculations that lead up to and prevail in the process of investment are not those suggested by the theory under consideration.

Time-preference is certainly not consciously present and it is hard to see how the institution of interest can rest upon a mental state which capitalists would fail to recognize as having any connection with their business. Indirect evidence, moreover, that estimates of time value are not an important factor may be found by considering the rates of interest on loans for different lengths of time. If a comparison of the utility or value of the capital sums loaned and returned, or of the goods these sums represent, played any part, then the longer the time intervening before the payment of the loan, the higher the agio or total of interest necessary as premium on present goods or discount of the distant future goods. If the preference for present possession grew in direct ratio with the length of the loan period, a uniform annual rate of interest would be demanded for all loans of 
equal risk. A thirty year loan of one thousand dollars, for instance, would receive six times as many annual payments of fifty dollars as a five year loan. But perhaps it may be argued that if time preference governs the loan market, a prospect of payment at a very distant date would call for a higher rate of discount than a short period loan, that if a five year loan is satisfied with $5 \times \$ 50$, a thirty year loan would demand $30 \times \$ 60$; preference for present goods and sums growing at a greater rate than the time interval before the final payment. The facts of the loan market, however, do not fit either of the above suppositions as to the rate of growth of preference for present possession with increasing remoteness of future payments, and do not, therefore, fit the necessities of the time-preference theory. Instead of a rate of interest on long time loans equal to or greater than that on short loans, we usually have a lower rate; evidence that an undisturbed annual income is desired and not the return of the whole equivalent of the "present goods" invested.

Something needs to be said about the idea of an exchange of present against future goods which has played more or less of a part in the agio theory. "The term "exchange" suggests two parties. "It takes two to make a trade." The investor or capitalist gives present goods in return for future goods. But who is it that gives the future goods? In the so-called "consumption loan" the borrower appears clearly 
to be the one who offers things in the future. But the consumption loan is one of the minor incidents of the modern economic system and may be passed over for the present. If it is not possible to make the idea of a trade in time-values fit the facts of the "production loan" and the use of capital in business, the major characteristics of the capitalistic world, it is evident that the factors suggested by it can play at most a very subordinate part.

Turning, therefore, to the production loan, we ask, who are the parties to an exchange in which present goods are given for future goods? Is there such an exchange between the capitalist as lender and the entrepreneur as borrower? The capitalist gives up present goods to the entrepreneur. The latter, however, far from consuming them, turns them into his business and looks for a future return. Obviously both entrepreneur and capitalist look for a future return. They share in the profits of capital. The capitalist because free from risk and the labor of directing the productive and commercial process contents himself with a part of these profits known as interest. Interest is "commuted profits."* What is really given in exchange, therefore, is not consumable quantities of wealth of different date-like the dinners of polite society - but different means and conditions of securing income. The entrepreneur receives the means of controlling the *Hadley, Economics, p. 270. 
productive or business process, the opportunity of making a gain by luck and the exercise of his business talents. The capitalist, on the other hand, receives an income without labor and often substantially without risk. But both devote present wealth to future income. If anywhere there is an exchange of present against future goods, it is not between entrepreneur and capitalist. We must look elsewhere for an answer to the question as to who gives the future goods.

If there is an actual exchange of earlier for later goods, connected in any way with the capitalistic production of wealth, apparently it must be between entrepreneur and laborer, the laborer being the seller of future goods. Now the wage contract may indeed be regarded as an exchange, but not as a conscious exchange of time-values. The laborer knows nothing of giving future goods. He has no goods to give, either now or in prospect. As Loria remarks, he is not so fortunate as to compete with the Roman Church in its traffic in future blessings. * He has only his labor-power. That may be used to produce goods which are to be finished and sold in the future, and so, by figure of speech, these products, and the labor-power itself, may be called "future goods." But this labor-power is a future good that can seldom "ripen" into a present good unless the employer consents to take it into his hire. So all that will *Il capitalismo e la scienza. Chap. I. 
be clear to the employe's mind is that with the employer's consent, he may work and receive wages. The goods he makes, he cannot think of giving in return for anything, because they are not his to give. All the characteristic features of an exchange are lacking. Yet if interest is to be accounted for as the agio in an exchange of time-values, the employe must be represented as giving commodities which he may never see in their completed form, whose amount and value he does not know, and - giving them subject to a discount. That discount, if there is a conscious trade in time-values, should satisfy the time-preference of both employer and laborer. But it requires no argument to show that the laborer knows nothing about such a discount. If he has not read the latest theorist he does not suspect that he has a rate of timepreference at all. Was any such rate ever mentioned in the contest between trade-union and employer?

Possibly the obvious absurdities of the idea of an exchange when applied to the wagecontract, - the one business relation in which present goods appear to be given for future goods on a large scale - are not necessary implications of the time-preference theory. Perhaps the use of the term "exchange" is simply an instance of unhappy terminology and may be avoided.* It might be argued that although *It may be suspected that if it were not for the apparent apologetic value of the idea of an exchange between present and future goods, the idea would have received little notice. 
the laborer is no conscious buyer or seller of time-values, the time-preference rate of capitalist and employer determines the rate of profit and interest. In that case, in trying to demonstrate a general preference for present over future enjoyment, the time-preference theorist may eliminate the laboring classes from consideration as irrelevant to the subject.*

To state the possibly consistent time-preference theory which may be reached by discarding the idea of a conscious bargain in timevalues between employer and employe, - the laborer might be represented as merely selling his labor for what he can get, while employers are led by competition to pay the discounted value of the product of that labor, the rate of discount being determined by the capitalist's rate of time-preference. This, of course, is possible only on the assumption that capitalists prefer present to future goods and at a definite rate of preference (at least, so far as the marginal supply of capital is concerned). That the competition of employers will give the laborer the full product of his labor discounted at not more than the "necessary" rate of discount, is of course one of the cheerful assumptions of

*The time-preference of laborers is of significance, in this connection, only in so far as laborers are capitalists and not always even then. A large part of the savings of the working class are such savings "for a rainy day" as would be made even if there were no interest receivable upon their accumulations. We may infer, therefore, that but a very small part of the capital funds of the world are affected in any way by the preference of laborers for present over future goods. 
the productivity theory of wages. This assumption, as will be shown in a later chapter, is questionable. Let us note only, that if one is willing to accept the productivity theory of wages in the form just stated, and also the idea of a definite rate of time-preference held by capitalists, we can get a very consistent theory of the rate and amount of interest and profit of capital. Capitalists and entrepreneurs as a class pay simply wages, nothing more.* These wages according to the theory just suggested are the discounted value of the total product, the discount being determined by the time-preference rate of the capitalist class.

This theory would not give us a complete theory of why there is interest at all. A complete explanation of the existence of the institution of interest and profit of capital would have to take definite cognizance among other things of the existence and conditions of a special class so situated that its rate of time-preference, if indeed it has one, can play no part in determining the share that it may get of the product of its labor. But the formulation of a complete theory of the existence of interest is a difficult and probably impossible task. In our view the method of theory should attack primarily the problem of the rate and amount of each share in distribution. As a theory of the rate and amount of the income of capital, the time-

*Setting aside rent and taxes and, of course, all payments not connected with the productive process. 
preference theory, as we have seen, may be stated in fairly consistent form. It rests on certain dubious assumptions in regard to the wage-contract, which will be reserved for later examination. The objection against the theory to be stated at this point, however, is the one suggested by our analysis of the psychology of investment. There is no comparison between present and future capital sums and no discoverable definite subjective rate of time-preference in the minds of capitalists and entrepreneurs. Whatever be the mental states of these gentlemen, they are not those suggested by this theory. Whether some other, happier formulation of the subjective condition of the capitalist class can be substituted for the time-preference notion, and give us a satisfactory theory of the rate and amount of capitalist gain, may be left to later consideration. At this point we are concerned only to show the failure of the time-preference theory.

Other than the contract between entrepreneur and laborer, the only transactions that suggest the idea of an "exchange" of present for future goods are the loan for consumption and the purchase of durable goods. To imagine the parties to a consumption loan as adepts in the utilitarian calculus, with definite time-preferences, may be less difficult than most of the trials of faith imposed upon us by the time preference theorists. However, it seems somewhat doubtful whether actual cases of such 
mental attitudes are discoverable. In any case it does not appear probable that subjective factors alone could account for the rate of interest on this class of loans. The lender, for instance, is less likely to think of his present and future "psychic incomes," than of the risk and of the rate of pecuniary return on the various investments, productive and unproductive, open to him. Is it not simpler to regard the interest payment on a loan for consumption as a derivative phenomenon and look for a fundamental theory of interest in the circumstances determining the income on productive loans and investments? After all, a secondary phenomenon such as the consumption loan affords too narrow a basis to support a comprehensive theory of capitalistic income.

When we come to consider durable goods, we are asked by the time-preference theorists to regard the purchaser as buying the future utilities or services given by these goods and, therefore, estimating the value of the goods he buys by discounting these psychic futurities. The most durable of all purchasable things is land. According to this theory, the price paid for a piece of land, or, in other words, the present goods given in exchange for the future goods to be derived as income from the land, must equal these future goods discounted according to the prevailing rate of time-preference. The price, in short, is the present value of a 
seemingly endless series of annual incomes.* Calculation of the price would have to proceed by adding the discounted values of the successive prospective annual returns until returns so remote were reached that their present value is infinitesimal. Obviously this is not and never was the method followed by any actual buyer of land.

With some goods of a less durable nature than land, as, for instance, in the case of a dwelling house, the calculation supposed by the time-preference theory, may seem less absurd. But how is it with goods of a still less durable character, a piece of cheap furniture, for instance, or a suit of clothes, or a box of cigars? Their utilities are spread out over. future time. Do we discount these utilities when we think of buying the articles? All, even the most evanescent goods, are to be consumed at a future moment, though that future be but a fraction of a second removed from the present. Must we be prepared to view the discounting of "psychic income" as entering into the determination of all commodity values? Here obviously we are beginning to approach the absurd.

Now possibly the application of its fundamental principle to the value of consumption goods is not necessary to the time-preference theory. It has been referred to here to show how far the bias in favor of psychological

*Böhm-Bawerk does not hesitate to call it an "infinite" series. 
theory has led the exponents of time-preference away from reality. If economics must get back to subjective factors, why not consider income as consisting of utilities rather than of the goods giving these utilities? And if utilities are income, why should not the income be capitalized? In other words, why not arrive at the value of a cigar by discounting the prospective pleasures of a smoke? "Logic is logic" even when it leads to absurdity. But obviously the unblenching subjective valuationists have led economic theory far from the observable facts of industrial life.

The departure from reality has come, of course, by stages. As Private Mulvaney would say, "one thing led to another." First, we were given the "economic man" - not a real man but supposed to be enough like a man of business, during business hours, to illustrate what might happen in the industrial world. Then this "economic man" developed into a Benthamite psychologist, but ever growing more subtle in his thinking, weighing and comparing utilities - after a time even of infinitesimal increments. Differential calculus was called upon to demonstrate the precision of his thought. When after a time the feeling of strangeness had worn off and our economist Frankensteins began to feel at ease with their monstrous creation, they saw that the clever creature could not be confined to estimating utilities that are all within one area or zone of time, 
as if he had no sense of time at all. No, he must look ahead and project his arrangement of utilities far into the future. So carefully does he distribute his consumption of commodities over the days, months, and years, that the least want satisfied at any moment of time has the same importance as the marginal want satisfied at any other moment. If by some investment of wealth, he disturbs his beautiful équilibre de la consommation, he knows exactly what rate of interest he must demand to compensate for the cost of this disturbance. * Such are the achievements of this hero of economic mythology. He has delighted our fancy, but the time has come to ask whether anybody ever saw anything like him in sober reality. And it is reality which economists profess to describe, though of necessity employing the method of abstraction. By "successive approximations," we have been led to hope, the abstractions of economic theory could gradually close in upon reality, almost attaining it. But obviously there are economic speculations that act more like successive dispersions from the facts of life.

Of course, we may expect that soon or late there will appear a sceptical reaction against the development of the principle of subjective valuation, and a disposition to appeal to the coarse judgments of the popular consciousness. Thus Lexis writes in opposition to the agio *Landry, L'intérêt du capital, Chap. II. 
theory - though apparently thinking only of Böhm-Bawerk's exposition and not of the finespun developments of recent writers - that "the question of the significance of a timedifference - the distantia temporis - between the beginning and end of a loan-transaction * * * was considered by the Canonists. The profit on a bill of exchange was justified by the difference in monetary standards and the distance between the place where the bill was drawn and the place of payment. But for the time difference all compensation was unconditionally excluded - evidence that the idea of a difference in value between a present and a future sum was as remote from the economic consciousness of that time as it is from the minds of the money lenders and house owners of today. But motives and considerations which do not demonstrably and consciously determine the actions of individuals and thereby cause collective phenomena (Massenwirkungen) cannot be regarded as factors of any importance in political economy (wesentliche Faktoren für die Volkswirtschaft).'

Possibly Lexis carries his scepticism too far. The refusal to consider anything but factors which are demonstrable and conscious to the popular mind, might exclude actually operating forces from examination. The popular mind is not acute in analysis nor conscious of its own processes. If, for instance, the question whether *Article Zins in Wörterbuch der Volkswirtschaft, Bd. II. 
estimates of marginal utility entered into the ordinary shopper's mind, were submitted to any group of plain people, the answer probably would be an hilarious negative. Yet while the average man would find it difficult to discover by introspection any of the subtle workings of the utilitarian calculus, relative marginal utility may after all have some influence on the distribution of his expenditures. Not that he carefully compares utilities. But if the marginal utilities of different lines of expenditure get out of alignment a distressing insufficiency at some point will lead to sober reflections and an effort to make a better proportioned provision for the different groups of wants. Moreover, imitation leads to a distribution of expenditures according to class standards, the outgrowth of the experience of the class and its gradual but not clearly conscious adjustment of expenditure to money income. The marginal utilities that affect the relative demand for different commodities on the market are to a large degree objective facts and social standards to which the individual conforms unconsciously.

Thus marginal utility although not recognized by the popular mind, is a factor to which economic theorists are justified in giving some recognition. But when we come to deal with time-values and preferences, we are entering a sphere where even the roughest, least conscious 
adjustment of expenditure to relative needs seems to be beyond the reach of probability. Manipulation of the "time-shapes" of income is practically impossible. To be sure, some successful spreading of expenditure, of the "psychic income" of the consumer, over the week, the month, even over the year is accomplished. It has been the study of many a pedagogical household. But who would claim that this has any perceptible effect on the business of deriving interest from capital investments? For longer periods of time, the unforeseeable changes in subjective and objective conditions of life, make both the experience of the individual and of social classes of no avail in effecting any rational equalization over time, of the stream of "psychic income." We have a right to demand that in theorizing, more definite and demonstrable factors be taken than the "time-shape" of income, "time-values," and "rate of time-preference." To reach general conclusions economists are obliged to assume the action of intelligent self interest, to picture life as more rational than it is in reality. The timepreference theory, however, carries rationalism to excess. By attributing superhuman powers to the economic man it becomes completely detached from the actual world. A highly hypothetical proposition, subjected to successive qualifications, may constitute the nucleus of a series of valuable "approximations" to reality. If, however, the first, obvious quali- 
fication is a complete denial of the initial hypothesis, there should be an end of experiment with such fictitious stuff. The time-preference theory is a remarkably consistent piece of theorizing and therein doubtless lies its great attraction. But it is spun out of nothing.

It is not denied that expectations, or let us say rather hopes and fears, of an increase or decrease in the proportion of income to wants may have some influence on saving, lending, and borrowing; may be among the psychic conditions out of which these acts sometimes arise. The business of life insurance depends on an appeal to such motives.* The amount of savings which seek interest-yielding investments may be affected by their intensity. Influencing the supply of loan funds they may have some influence on the rate of interest. But to grant that these expectations, hopes, and fears have an influence on the rate of interest is far from admitting that they are a direct determinant, sufficiently definite and powerful, to be given a place in a carefully formulated general theory of the rate of interest. And in any case they are subordinate in importance to most of the purposes and calculations that rule in the direct investment of capital in the

*It should be noted, however, that in buying life insurance, the one really clear and important case of an occasion for comparing amounts of consumable wealth of different periods with reference to a difference in the state of provision for the wants of these periods, the preference is for future goods, and, therefore, the reverse of the time-preference called for by the theory under consideration. 
productive process. Of these calculations, we have seen, the concept of time preference gives a false notion. We may conclude, therefore, that the effort to reconstruct Böhm-Bawerk's theory by eliminating the technical factor and basing the argument exclusively on subjective estimates of time-value, cannot contribute much to the elucidation of the problem of interest. The idea of a sacrifice of present goods in return for future goods may have some value in the apologetics of the capitalistic system. That, however, is of no concern to disinterested economic theory. The important fact is that time-preference has too little relation to the actual forces at work in the industrial world, to serve as an explanation of the amount and rate of capitalist income. 


\section{CHAPTER IV}

\section{THE ABSTINENCE THEORY}

The controversial success of the Austrian theory of value has created a bias in favor of explanations of economic phenomena in terms of subjective valuation. It has fostered the ideal of a unitary theory based on some psychological factor. In the time-preference theory of interest we have the extreme expression of this tendency. It is, however, the only modern psychological theory of distribution which professes to offer all the elements of a theory. If we reject it, we must turn to objective, nonpsychological factors for at least part of the explanation of the problem. The only other theory which may be called subjective or psychological is the abstinence theory. Recent adherents of the latter, however, do not claim completeness for it. It is advanced as a treatment of the factor of supply of capital only, as part of a dual theory of interest in which demand for capital is described as starting from technical and business facts. All that we need to consider, therefore, in reference to this theory is whether it states a factor affecting supply of capital sufficiently important to warrant its inclusion in a general theory and whether it correctly represents the mechanism by which this factor comes into play. 
In favor of the abstinence theory it may be said that it gives a possibly less definite, but also less questionable, description of the mental states of the investor than the time-preference theory. In some modern versions the concept of abstinence is practically converted into that of time-preference. It is possible, however, to formulate the abstinence theory in such a way as to avoid the erroneous conception of an exchange of present against future goods in the form of an exchange of a present capital sum $\mathrm{C}$, against a lump sum $\mathrm{C}+\mathrm{i}$ (i representing interest). The exchange may be taken to be that of $\mathrm{C}$ against a series $\mathrm{i}, \mathrm{i}, \mathrm{i}, \mathrm{i}, \mathrm{-}_{\mathrm{C}}-$ of regularly recurrent sums. Abstinence is represented as the subjective cost of a permanent, regularly recurrent (usually annual) income, obtained without labor.

Now does this theory give us an entirely acceptable account of the psychology of saving and investment, of supply of capital? The answer will depend in part upon whether saving and investment really involve a subjective cost. If the term abstinence were taken to mean merely any abstention from consumption in favor of investment, it is obvious that it would frequently involve no perceptible subjective cost. But even when used in this broad, colorless sense, the term would be too narrow to apply to the mental states involved in all cases of investment. In many instances sums are invested that would not have been spent for 
consumption goods even if there had been no possibility of investing them. In such cases there is, of course, no abstention or abstinence from consumption. The abstinence theory does not, therefore, at least in its cruder form, convey an entirely truthful impression of the psychology of the capitalist. Its implication of a subjective cost is true of only a limited part of the field of investment. Saving and investment without perceptible subjective cost or hardship occurs not only when there is an unspent residuum of an income so large that it would be distressing to the recipient to find ways of spending it. The maintenance of a capital sum once saved and its increase by accumulation at compound interest probably means little subjective cost to the confirmed saver, even if he be the recipient of only a moderate income. Besides the saving of individuals there is growing up an increasingly important saving of an impersonal character. By depreciation accounts, the managers of corporations provide for the maintenance of capital. and by the accumulation of surplus for an increase of capital, without the slightest consciousness of abstinence on the part of the majority of stockholders. And there is the "manufacture of credit" by banks. Whether this, however, constitutes an increase of capital in a real sense is a disputed point.

It must be recognized, however, that modern expositions of the theory do not attribute all 
saving and investment to abstinence. They aim primarily at an analysis of the factors determining the rate of interest. As they view the matter, it is the subjective cost or abstinence of the marginal savings that is just paid for by the rate of interest, the rate established by the equalization of demand and supply. Savings other than the marginal may be subject to little or no cost, but receive the benefit of the rate that must be paid in order to overcome the marginal saver's reluctance to undergo the necessary abstinence. The greater the amount of capital available throughout the field of industry, the less is gained by its use at the margin and the lower in consequence the rate of interest. If the rate rises as a result of greater demand, increased savings will be induced; if the rate falls, the marginal savings will fall off because of diminished inducements. It is implied, therefore, by the theory, that saving rises and falls with the rate of interest though not necessarily in the same degree. Thus it regulates the supply of capital and thereby its marginal gains, in such a way as to establish a rate of interest that pays for the abstinence of the marginal savings. And it is further implied that the changes in the supply of saving necessary to bring about this equilibrium between rate and abstinence, are in the saving which can be called marginal and involves the cost of abstinence. 
The interacting factors supposed to determine the rate of interest are stated in terms of demand and supply. This gives occasion for some criticism of a more or less formal character. What is the meaning of "supply" of capital? Is it the supply of loan-capital only or of the total of capital whether borrowed or owned by those who employ it? Since the demand is represented as being regulated by the marginal "productivity" of capital, and this depends on the total of capital used, it is necessary to take the word supply as signifying the total. Now what rate have we to consider in this discussion that of profit or that of interest? As the total of capital is under consideration, it is evidently the rate of profit. Yet the theory professes to be a theory of interest.*

If the rate of profit and that of interest always varied together and in the same direction, it would not be misleading to represent the rate of interest by that of profit in a discussion of the interaction of demand and supply. There are theoretical grounds for expecting these two rates to move together. There appear to be, however, historical instances of their failure to do so and even of their going in opposite directions. Now as saving and the supply of

*Sometimes the return on marginal investments of capital is represented as being interest only, the entrepreneur in search of profit having borrowed capital until all excess of profit over interest has disa ppeared on the last portion borrowed. Here the habit of thinking of infinitesimal increments has led to the improbable conclusion that entrepreneurs will do and continue to do things which result in no gain to themselves. 
capital are represented by the theory under discussion as being in response to, or induced by, a rate of return, there arises the difficulty that some savers are affected by the rate of interest alone, others by the rate of profit as well as by the rate of interest. Those who are capitalists only, unwilling to run risks, without ability or inclination to manage a business, will not in their saving be affected by the rate of profit at all, unless that rate in its movement drags the rate of interest with it. The entrepreneur, however, in his saving will be affected by both rates, though conceivably in conflicting ways. If the rate of profit declines, he has apparently less inducement to save capital than before. If at the same time, however, the rate of interest should remain unchanged, or should rise, he might have a stronger motive than before for owning the capital he uses instead of borrowing. Or the capitalist and investor within him, rather than the entrepreneur and speculator, might develop and feel himself drawn to increased saving by the prospect of a safe interest return. If, however, we may assume that the two rates move in the same direction and in such degree as to leave always the same margin between them, all classes of savers may be regarded as affected in much the same way, and one difficulty of the theory under consideration will be overcome.

We have seen that the statement of the theory of interest in terms of demand and 
supply leads to some ambiguities in regard to the meaning of the word supply. In like manner it forces us to employ the term "demand" in a somewhat metaphorical sense in the case of the entrepreneur who saves and uses his own capital. Can such capital be described as supplied in response to a demand except by twisting the meaning of the language? Who makes the demand?

Of course these objections to the modern form of the abstinence theory are largely formal, striking at defects and ambiguities of statement and the awkwardly hypothetical character of its propositions, but not calling into question the possibly large measure of truth it may contain. The pedagogic rather than the scientific value of the theory is impugned. Yet in spite of the risk of a strained form of statement distorting the perspective and throwing minor factors into misleading prominence, it would probably be maintained by many writers that the demand and supply formulation of the theory of interest is the most practicable and compact form of expression possible. The pertinent question is, Does it give an approximately true description of the factors at work? More cannot be expected from any theory and unreasonable demands must not be made of the theorist.

There are, however, objections of a more material character which may be made to the 
abstinence theory. It involves two fundamental propositions which analysis will call into question. These are:

First, the total amount of capital rises or falls with a rise or fall of the rate of profit (or interest). In this manner the rate of return to capital is regulated and kept from extreme fluctuations. A corollary indicates that the rate cannot fall to zero and the theory thus appears to account for the necessity and continuance of interest on capital as well as for its rate and amount.

Second, the changes in the amount of capital which are regulative of the rate of return are brought about through the operations of the marginal savers.

Granting for the moment the substantial truth of the first proposition, although we shall see later that it is not always valid, let us examine the second. The validity of this proposition is vital to the abstinence theory. If changes in the "supply" of capital regulative of the rate of return on capital are not determined primarily by the course of marginal saving, of saving determined by mental states affected by the expected rate of return, then the decisive factors must lie on the side of "demand," or in any case, be of an objective rather than of a subjective character.

Now, to begin with, are marginal savings relatively of sufficient amount to have a decisive influence on the rate of profit and interest? 
Does the tail wag the dog? There is to be sure, no way of deciding definitely what proportion of the world's capital owes its existence and maintenance to the marginal saver. The statistician may seek for data in regard to the sums which are saved and invested, but there is no numerical record of the mental states attending such saving. We can be guided only by our general impressions. To the present writer it appears that whatever may have been true in some communities and in the earlier stages of capitalism, abstinential, marginal savings are today relatively unimportant. They appear very small indeed when we set over against them - (I) the large accumulations of capital made without thought by recipients of large incomes, the unspent residua of income of careless, happy spenders; such accumulation proceeding at a more or a less rapid rate according as the larger incomes rise or fall; (2) the impersonal creation of capital made by managers of corporations accumulating surplus out of earnings without consulting the willingness of the stockholder to abstain from consumption; (3) the stores of capital amassed in the past, which, whatever may have been their cost of abstinence in the saving, are now maintained inviolate from all thought of ever being consumed, and incapable, therefore, of decrease except through misfortune; (4) the "rainy day" savings which would be made even if there were no such thing as interest or profit on capital, and (5) 
as factors diminishing the supply of capital, the waste and destruction of capital in unproductive, unfortunate, or fraudulent enterprises; the wreckage of promoter and speculator, and the wasteful and destructive armaments of military nations.

Moreover whatever be our estimate of the quantity of abstinential saving and of saving affected at all by the contemplation of a rate of interest, we must make a considerable deduction for that portion which proceeds in a manner directly contrary to the assumptions of the abstinence theory. To some who experience the pangs of abstinence a fall of the interest rate is the occasion for saving more not less, a rise the occasion for saving less. "As Sargant has pointed out," says Marshall, "if a man has decided to go on working and saving till he has provided a certain income for his old age, or for his family after death, he will find that he has to save more if the rate of interest is low than if it is high." * How large is the deduction we must make for saving which proceeds contrary to the expectations of the theory, there is no way of estimating. It is sufficient to make it doubtful what the effect is on abstinential, calculated savings taken as a whole, of any change in the rate of interest and profit. Three hypotheses may be suggested. First, that abstinential savings as a whole rise and fall with the interest rate, moving in the same *Principles of Economics, 6th edition, p. 235. 
direction. Second, that they move in the opposite direction. Third, that the opposing tendencies are equal, so that changes in the interest rate make no change in the total of abstinential saving. Only the first of these is in accord with the necessities of the abstinence theory. But are we justified in rejecting the other two as obviously impossible? And in any case can the net resultant of the opposed tendencies be of sufficient amount to be considered an important factor in determining the rate of return on capital?*

*The consideration of conscious, deliberate, and calculating saving alone - leaving out of view the unconscious and impersonal forces accumulating, maintaining, or wasting capital seems likely to leave one in doubt as to the exact effect of a given change in the interest rate. Thus Marshall after giving an illustration of the idea we have quoted from him, proceeds: "It is then possible that a continued fall in the rate of interest may be accompanied by a continued increase in the yearly additions to the world's capital. But none the less is it true that a fall in the distant benefits to be got by a given amount of working and waiting for the future does tend on the whole to diminish the provision which people make for the future ** * that a fall in the rate of interest tends to check the accumulation of wealth." Here we have the traditional view of the effect of a fall in the interest rate expressed in terms of tendency and "as a whole," while the opposite effect is allowed as "possible." The most thorough discussion of the mental states of savers is probably that by Professor Gonner. Gonner concludes "alterations in the rate operate in different directions. But no positive and universal determination is possible, for the forces are irregular and exist in no fixed relations. It is, however, clear that it is incorrect to say that at a given time there is only one rate of interest able to bring about a particular amount of accumulation. On the contrary, different rates may bring into being the same amount of accumulated wealth and capital." Interest and Saving, p. $75 \mathrm{ff}$. 
For the sake of argument let us grant the first of the three hypotheses. Then the adherent of the abstinence theory is confronted with the logical necessity of showing that other factors determining supply of capital act in the same direction as the marginal savings, in their total effect. And, furthermore, if the abstinence theory is to be more than a description of a very minor factor, if it is to be more than a fraction of a complete explanation, it becomes necessary to prove that the action of the various forces determining the amount of capital other than the marginal savings, must be determined by the latter. In other words, these other forces apparently so much greater in their effect than the operations of the marginal saver, must be shown to be led or started by the marginal saver in the direction in which he is going.

That obviously is an absurdity. What, for instance, is the possible relation of the marginal saver's worries, to the large quantities of capital supplied by those who cannot be said to save, for that connotes some thought and purpose, but who accumulate large sums by failing to spend all they receive? Assume a more or less stable standard of living among those whose income is large enough to make some accumulation of capital habitual and continuous, and we can see that changes in the rate of accumulation easily follow corresponding changes in the volume of income. There is 
no searching of heart and of pocket-book to see whether some anticipated though uncertain percentage offers sufficient reward for the pangs of abstinence. It may be that there is some addition to or substraction from the world's total of capital brought about by the contemplation of the movements of the interest rate, but, in any case, the abstinence theory gives an ill proportioned picture of what actually takes place by its emphasis on savings induced by expectations of given amounts of reward. It carries the dubious implication that more or less of calculating abstention from consumption makes a great difference and that the prime factor in bringing things to an equilibrium is a mental occupation with a future fact, that is, with an anticipated rate of gain. Is it not a truer view to regard as the moving factor one that belongs to the past rather than to the future, the fact of increased or decreased income?

The mainspring of the great movements of the supply of capital cannot be found in the marginal saver's mind. This is the opinion forced upon us when we consider the accumulations made without thought and effort out of large incomes. In like manner we fail to find any discoverable connection between painful abstinence calculations and the reservations for surplus made out of the earnings of large corporations or even of smaller business units. And what have considerations of abstinence to do with maintaining in the face of any fall of 
the interest rate yet experienced, the capital sums once saved? What pang of abstinence could ordinarily be balanced against the grief of parting with capital? And finally when we come to the various forces wasting and destroying capital, as they manifest themselves especially in times of crisis and of war, we may confess our inability to give a full explanation of their appearance, and yet have no hesitation in declaring that the marginal saver's states of mind count for nothing in these affairs.

If the calculations of the marginal saver are not the mainspring of the great forces determining the amount of capital in the world, the abstinence theory fails as an explanation of the quantity and rate of capitalist income. Our argument has led to the conclusion that no simple, easily formulated psychological factor can account for increase or decrease of capital. The prime factors must be objective. How large is the product of industry and how much of it is left after wage earners and other recipients of small pay have drawn their share? In other words what is the income in the shape of rent, interest, and profits out of which capital is accumulated? Out of which it may almost be said to accumulate itself. And what are the factors determining the waste and destruction of capital, the only factors capable of causing a positive decrease in the total of capital and not merely a slackening in the rate of its increase? Such are the overwhelmingly important forces 
making the supply of capital what it is. They act in entire independence of the marginal saver's supposed balancing of the cost of abstinence against the attractions of an anticipated reward. They are objective rather than subjective factors and will not fit the logical necessities of the abstinence theory. And it may be added, they are equally recalcitrant to the needs of the time-preference theory. It matters nothing to the argument whether we speak of the cost of abstinence or the cost of waiting, the reluctance to abstain from consuming or the reluctance to postpone consumption. The fact is that no unobjectionable formulation of the process we are trying to explain is possible in terms of anything psychological.

It appears to the writer that sufficient grounds have been given for rejecting the abstinence theory and its possible variants. Some consideration, however, may be given to the question whether marginal savings move with the greater forces determining supply of capital and in the same direction. Or, to state the question with a different emphasis, do the great forces other than the marginal saver's operations, act in the same direction in response to changes in the rate of interest and profit as the marginal savings, assuming the latter to act as described by the abstinence theory? In that case, although neither of these two sets of factors determines the other, the fact of their being more or less synchronous and parallel, would make it possible 
to maintain that the abstinence theory describes a part of the forces determining supply of capital, though a very small part, and that as long as we care only for the direction of change and not for the amount, the abstinence theory could predict correctly what will happen under given conditions. However, not even that slight concession may be made to the value of the theory. It isn't true that the decisive factors always and necessarily increase or decrease the total of capital according as the rate of interest and profit rises or falls. These factors may at times act in that manner, and thus prevent large fluctuations in the rate of return on capital, but, as will appear, such is not their invariable action. In fact it is not possible to formulate any "law" or simple general proposition in regard to the influence of the rate of interest or profit, on increase or decrease of capital.

Leaving out of view the marginal saver and giving attention only to the great and decisive factors determining supply of capital, let us ask first what happens when the rate of interest and profit goes up. Usually we may expect an increase of capital. This will be at an accellerated rate if the rise in the rate of interest and profit indicates a rise of the total of interest and profit; if, for instance, there has been a great advance in productive efficiency, or increased opportunities for the exploitation of new lands or cheap labor. In that event there 
will be a rapid accumulation of capital in the shape of unspent residua of income and large reservations for capital use out of gross profits by business managers. At such times it may almost be said with truth that the opportunity for large gains creates the capital to exploit the opportunity. A less rapid growth of capital may occur when the higher rate of interest and profit indicates the higher productive margin at which destructive influences, as for instance a great war, have left the diminished total of the world's capital. In spite of the high rates the total income in the shape of interest and profits is less than before and the rate of growth of the total capital, will, therefore, probably be less. Whether slowly or rapidly, however, the total of capital may be expected to grow when the rate of return goes up. And yet this is not the inevitable outcome because there may come into play the forces wasting and destroying capital, forces so unpredictable and erratic as to have the appearance of extraneous and accidental factors from the view point of economic theory.

If the movement of capital in response to a rising rate of interest and profit is, on the whole, in accord with that assumed, though not correctly explained, by traditional economic thought, the same cannot be said of the results of a fall of the rate of capitalist gain. If, what is the most probable case, the fall in the rate of return is due to the lowering of the productive 
margin brought about by the increase of capital, the total of income in the shape of interest and profit has been increased. New supplies of capital seeking investment receive only a low ratebut the recipients of interest, profit, and rent, as a class, are wealthier than before. The accumulation of new capital out of these incomes might therefore be expected to continue in greater rather than in lesser volume.

The case of a lowered rate signifying a general decline in productive efficiency and, therefore, a decrease of the total of incomes in the shape of interest and profit, is so purely hypothetical and remote from our experience, that it seems hazardous to speculate concerning it. Capital might simply show a decreased rate of growth. There would probably still be some saving for a rainy day. And even if the total of capital did not increase there need be no decrease. The large capital accumulations of the past might be jealously guarded against the desires of spendthrift and consumer. The same considerations probably apply to the case of a general diminution of interest and profit brought about by labor gaining a larger proportion of the total product of industry. In fact all conceivable conditions seem to include some saving, that is, some addition to the stock of capital, and a holding on to what has once been saved. 
Whatever conditions we assume, it seems difficult to prove any probable, positive decrease in the total of the world's capital. In what appears for an advanced industrialism the most likely cause of a decline in the rate of capitalist return, that is the lowering of the margin of investment brought about by the increase of capital itself, the result is an accelerated increase in capital. But if such is the case, what keeps the rising tide of capital from forcing the marginal rate of profit downwards until it vanishes from sight? What makes the continuance of the capitalistic system itself possible?

Economists apparently have not given much consideration to the distressing thought of a rate of profit reduced to zero. The classical writers, however, frequently raised the question as to what agencies resisted the strong "tendency of profits to a minimum." First among these, says Mill, is "one which is so simple and so conspicuous, that some political economists, especially M. de Sismondi and Dr. Chalmers, have attended to it almost to the exclusion of all others. This is the waste of capital in periods of over-trading and rash speculation, and in the commercial revulsions by which such times are always followed."* To "over-trading and rash speculation" we may add the destruction and waste of capital by militarism. The second of the "counter-agencies" according to *Principles of Political Economy, Book IV, Chap. IV. 
Mill is "improvements in production." So far it appears that capitalism is saved by waste and progress. A third factor, mentioned by Mill, "the perpetual overflow of capital into colonies or foreign countries," indicates that the day of reckoning may be postponed by the extension of capitalism into new territory.

Thus either by the destruction of the superfluity of capital, or by the enlargement of opportunities for investment through invention or geographical expansion, the rate of interest and profit is kept alive. We shall not undertake a thorough examination of the extent to which the fall in the rate of capitalist return itself calls out these counteracting forces. That a low rate of interest stimulates speculation and unsafe enterprises is fairly obvious. The influence of the over-accumulation of capital on governmental expenditures and imperialistic policies is no secret. Of the restlessness of a world forced to seek an ever expanding field for investment we have abundant evidence. The worry of our age has been its redundant capital.

Our discussion has shown the impossibility of formulating any simple general law in regard to the response of capital supply to a changing rate of return. There is no definite supply price in the shape of a rate of interest for any given amount of capital. On the whole a rise in the rate of return tends to be followed quickly by an increased supply. On the other hand, a fall in the rate of return may find no immediate 
check. When finally checked it is by such forces as an expansion of the capitalistic area, progress and invention in productive methods, and large waste and destruction of capital.

The views in regard to the supply of capital which we have set forth, lack the attractive simplicity of the abstinence theory. But that simplicity, like the excessive rationalism of the time-preference theory, is not found in the actual phenomena. The theory supposes a more refined and persistently followed utilitarian calculus than seems probable, or possible to real human beings. The writer does not deny, of course, that there may be serious reflection on the question of spending less and saving more. To a rationalistic view the utility of saving might appear to be increased every time the interest rate moves upward a little. But is the problem of the relative attractions of saving and spending raised in anybody's mind every time the interest rate changes? Are not such considerations rather occasional? They help to establish habits of spending or saving a certain amount. Then if the income out of which saving is made rises, an increased "saving" takes place without thought of what rate of interest may be obtained by it.

To be sure it is conceivable that very great and sudden changes in the rate of return might shake people out of their established habits into deliberately saving more or less. If the 
rate, for instance, were suddenly to jump to twenty per centum, saving would have attractions it never had before. A sudden drop to one-tenth of one per cent. would have most disturbing and unpredictable effects on those who had hitherto been in the habit of saving. But do changes of such amount as experience teaches us to expect, lead to new calculations of how much we may save or spend every time they occur? When the rate rises from, say four per cent, to four and a fraction, or even to five; or falls from four to three and a fraction, or even to three per cent, how many are there who form new resolutions? An expected return on investment of some kind may give an inducement to saving, a support to the habit of saving, - for some persons, a general reason for saving at all. But that does not mean that different definite rates of prospective return directly determine the amount of saving and maintenance of capital. The implication of the abstinence theory that expected rates of return have this definite determinative effect is an unproved assumption. But even if the painful calculations of some marginal savers pursue the course described by the exponents of the abstinence theory, are they of sufficient consequence to make any real difference? Are not their contributions to the current supply of capital so insignificant compared with those from other sources, that a general theory of the income of capital is warranted in disregarding them? 
The great factors determining the supply of capital, we may call, for lack of a better term, objective, in contrast with the subjective determinants set forth by the abstinence and timepreference theories. Set over against these objective forces, the calculated, abstinential savings appear, to the extent of their tenuous being, a mere epiphenomenon of our modern industrial system.

If the view just presented gives a substantially true picture of what takes place in the existing world of capital accumulation and investment, it follows that the theory of the rate of interest should aim first to account for what we have called the objective factors. It should inquire into what determines the opportunities of a gainful use of different anlounts of capital, i. e., it should give us first of all a theory of the origin and rate of profit. In doing this it will be well to avoid metaphor and not to speak of a "demand" for capital. A large amount of capital never changes hands and there is no question as to who is to use it and upon what terms. It is neither demanded nor supplied. It is merely owned and used. When the rate of profit has been accounted for, theory may proceed to the problem of the rate of interest, the problem of how profit is divided between capitalist and entrepreneur.

The more fundamental problem of the rate of profit which makes possible a rate of interest, cannot be stated satisfactorily in terms of 
demand and supply. Theory may recognize that the amount (not the supply) of capital is a determinant of the rate of profit, and also that saving affects that amount and thereby the rate of return. But saving should not be put forward as a factor acting independently or as being quantitatively determined by factors independent of and distinct from the objective, technical or business factors, which make the rate of profit. In other words, saving should not be represented as determined by subjective factors. While such factors may affect some saving, the decisive, regulative changes in the supply of capital cannot be attributed to them. The actions and purposes which determine conscious saving, the calculations of abstinence, such as they are, cannot be co-ordinate in importance for the theory of profit, with the facts which determine the gains of capital. There is no bargain made in saving. The saver as such has nothing to say in the matter of making capital yield a profit. It is the users of capital, their skill and opportunities, that really signify. The usual demand and supply formulation of the abstinence theory, by giving to saving and abstinence on the one side, an appearance of as great importance as that of the objective factors on the other, gives a misleading perspective to all the factors at work. The habit of thinking in terms of demand and supply has its drawbacks. We need to break away from the see-saw of demand and 
supply to reach a just appreciation of the relative importance and direction of the forces which make the existing amount and rate of capitalist income.

The objection to the abstinence theory coming especially from socialistic quarters, that the large capital accumulations of the rich are subject to no cost of abstinence, was apparently met by limiting the significance of abstinence to the marginal saver. But this answer, we have seen, is not conclusive. It was not proved by the adherents of the theory that abstinential savings are of sufficient amount to be in any way regulative of the rate of interest. The capital which comes without abstinence, with its larger volume and more rapid changes, leaves the tendencies and effects of abstinential savings a purely secondary movement, of imperceptible influence on the actual rate of capitalistic income. We need not look to the abstinence theory for any clear light on the problem of the amount and rate of interest and profit. It fails as fully as the time-preference theory to show primarily subjective factors as the direct determinants of the rate of income.

Our criticism of the abstinence theory has aimed to show that it fails to account for the amount and rate of return on capital. There is the further question as to why there is interest at all. Why is it possible to obtain an income without labor? Whether an answer to this question entirely satisfactory to all students 
can ever be given seems somewhat doubtful. In any case, among the data necessary to an explanation of the existence of the institution of interest there are legal and historical factors with which the economic theory is not fitted to cope. Now it may be granted to the abstinence theory that it has brought to light, in the cost character of the abstinence necessary to some saving, one of the conditions essential to the existence of interest. If saving involved no sacrifice, the volume of capital would rise to the point of making interest impossible. Capital would be free to all. But if it should cost nothing to save, it is evident that income must consist of "free goods." The character of the abstinence involved in saving is, therefore, not only one of the conditions of the appearance of the institution of interest but of practically all economic life. It is a proposition of such general character that it seems pedantic to cite it at all instead of taking it for granted. However, we need not object if an explanation of the existence of capitalist income should take some cognizance of the fact that capital depends on saving, and that because our income consists of "economic goods" and not of "free goods," saving involves abstinence. But if we seek an explanation of the existing amount of capitalist income, the consideration of abstinence and in general of subjective factors, is of slight advantage. We may grant too that the concept of abstinence may play some part in 
capitalistic apologetics. With that however we are not here concerned. The obviously important facts for the purposes of the theory we are seeking, are not subjective but objective in their nature; and to these our attention must now be directed. 


\section{CHAPTER V}

\section{THE PRODUCTIVITY THEORY OF INTEREST}

When we turn to the study of the objective factors of the process of capitalistic production and distribution, we are confronted by various attempts to deduce interest from the "productivity of capital." These productivity theories differ in clearness and expository detail, in the extent and manner of combination with other theories, and in the definition of capital taken as a starting point. The most popular form operates with a conception of capital as a group of concrete goods used as instruments of production. With such instruments, if of the right kind, labor obviously can produce more than without. This excess of product is imputed in more or less metaphorical language to the concrete capital goods, and the assumption is made that it corresponds in some way with the amount of income that the capitalist normally receives from the use of his capital.

Two problems are presented by this form of the theory. First, how can the part due to capital in the joint product of capital and labor be marked off from that due to labor? And secondly, how can we ascertain what part of the product imputed to capital is to be regarded as replacement of the capital used up, and what as net remainder may be stated as a percentual 
return upon that capital? Or in other words, as it is the value of the capital itself which must be deducted from the part of the product imputed to capital, how is that value determined?

To determine the product to be imputed to capital it would apparently be necessary to know what labor can produce without capital. If all excess of product above this, no more and no less, is to go to the capitalist, wages would have to be just equal to what the labor employed could have produced without the aid of capital.* It does not appear to be easy to determine precisely what that amount would be. Nor does this determination of wages appear probable when applied to certain grades of labor. It is pretty clear, for instance, that many kinds of skill and ability would be of very little use outside of capitalistic industries. If it were true that labor gets only what it could produce without capital, then skilled labor, on the whole, would receive the lowest wages paid in any industry. It would be inexpedient to take up the consideration of the theory of wages at this point, but it should be noted that the interpretation of the productivity theory just given suggests a view of wages that cannot be brought into accord with any of the theories of wages prevailing at present. Moreover, its implication that none of the productive advantages of

*To avoid complications of statement, differential profit and rent are omitted from consideration at this point and throughout our discussion of capitalist income. The problem is that of the division of marginal product. 
capitalism go to the wage-earner would not be very attractive to most exponents of the productivity theory.

The form of the theory now most in favor, however, does not clearly impute to capital the total of product in excess of what labor unaided by capital could produce, but only an amount depending on a rate determined by the productivity of the last and least productive unit of capital taken on. This "marginal" rate forced upon the entire amount of capital leaves that part of the product of the earlier increments which is in excess of this rate, as something that does not go to the capitalist but to some other "claimant" in the distributive process to the landowner, or to the entrepreneur, or to the laborer. This method of calculating imputed returns is also applied to labor. Alternately injecting now a "dose" of capital, now of labor, we are asked to observe the productive effect of each to get its "specific productivity" and rate of payment. It is to be noted that the dose must be a homeopathic one. A large increment of either factor would necessarily call for a simultaneous increase in the other. In that case the additional product obtained would be a joint product of capital and labor, not a "specific" product of either, and there would be no way of ascertaining what proportion of it should be imputed to each. This 
gives an air of extreme unreality to the theory in question. Is the calculus of small doses a possibility in the conduct of actual business?

Granting, however, for the sake of argument, that in some way, the return to be attributed to capital can be calculated, the popular specific productivity theory is next confronted with the difficulty of the second problem mentioned above, the problem of determining the value of the capital. Critics of the theory have shown conclusively that it fails at this point. How can you compare the product with the capital to which it is imputed in such manner as to ascertain a percentual rate of return? The goods produced and the "capital" that "produced" them are of unlike physical character and, therefore, incommensurable. How can you express yards of textiles as a percentage of the looms from which they have issued? Physical measurements give no basis of comparison. Evidently we must resort to market values. If we ask how the capital good gets its market value, we are told by modern economists that it is derived from its product. But why is not the value of the capital good equal to its entire product? Why is there in the value of the product a surplus called interest? Because, for some reason, the entrepreneur will not pay for the capital good more than the discounted value of its products. It appears, therefore, that the discount and interest rate, which the productivity theory represents as 
arising from a comparison of values, is assumed in getting the value of one of the terms of the comparison, - an obvious case of circular reasoning. This objection to the popular form of productivity theory is a logical inference from a theory of value that regards demand based on estimates of utility on the part of buyers, as the chief, or one of the chief, determinants of value. It is hard to see how those who hold the Austrian theory of value can accept a productivity theory of interest while defining capital as concrete goods used as instruments of production.

If instead of looking forward to the product for the source of the value of the capital good, it be permissible to look backward to its expenses of production, a productivity theory based on the concept of capital as consisting of concrete goods, would still be exposed to the criticism that it is reasoning in a circle. A view of the entire process of production shows the investment of capitalists and entrepreneurs, as a class, to consist of advances to labor. If we might assume these advances, that is wages, determined in some way independently of the product of capitalistic industry (by the "cost" of labor, for instance) we should get a value for capital with which the net product might be legitimately compared in calculating the percentual rate of return. But the theory we are considering confines the term capital to concrete goods used in the later stages of production. The price 
of these goods includes not only payment for the labor employed in making them, including the labor of all the preparatory stages, but also accumulated interest and profit. Obviously it is not possible to get the value of the capital good without assuming a rate of income upon capital. Whatever method this theory takes of accounting for the value of capital goods, involves it in a vicious circle.

We might therefore regard the theory we have just considered as disposed of, and pass on to other variants of the productivity theory. It is desirable, however, to point out some difficulties arising from the restricted concept of capital employed by this theory. Obviously the entrepreneur expects to gain at least the rate of interest from all of his business outlays, not merely from what he spends for "capital goods," but also from his expenditures for labor. The exponents of the specific productivity theory say nothing about the interest earned by the employer's pay roll. Yet the fact of this interest cannot be denied. Or, is it an illusory phenomenon? Could it be argued that all interest grows out of capital goods alone but that it is spread as a uniform rate over the entire investment of capitalist and entrepreneur? If this were the case, the actual rate known to business men would be smaller than the rate of productivity of the capital goods, and the productivity theory, while indicating the source of interest, would stand in need of further 
development to explain how the actual rate of interest is established. The problem confronting the productivity theorists would be the inverse of that met by Karl Marx. To obtain the rate of profit Marx had to show how the surplus value due only to "variable capital," i. e., to what is paid for labor, is assigned to and expressed as a percentage of, the total investment, of both "constant" and variable capital. The productivity theorist would have to meet the problem of spreading a surplus from the use of the "constant" capital, the concrete capital goods, over the entire capital, variable and constant. Unlike Marx they have made no effort to solve their problem.

Or may interest on the wages fund be regarded as a derivative income? Could it be argued, in a manner analogous to the reasoning of the fructification theory, that, because the capitalist can obtain interest from capital goods, he will refuse to buy labor except at a discount which will yield him the same rate of interest? But capital goods have no productive value unless served by labor and the entrepreneur could not refuse to buy labor and turn entirely to capital goods. If, under such conditions, labor submits to a discount, that fact needs to be explained. The productivity theory suggests no explanation.

Such are some of the difficulties of the form of the productivity theory which we have been considering. They arise out of the restricted conception of capital. The usage of the business 
world is to regard all outlays whether for labor or for "capital goods," as an investment of capital and to expect or hope for a return in profit or interest on every part of the investment. In taking capital in the sense of concrete instruments of production, the theory fails to take account of important interest-yielding investments. Moreover, this restricted concept of capital, limits the view to one segment of the long process of capitalistic production. It has nothing to say about the labor that made the "capital good," the machine, for instance, nor the conditions under which that labor was employed. It does not go back to the beginning of the productive process, but fixes attention on one of the later stages in asking what is added to total product by the use of a given capital good. It proceeds, in the language of Böhm-Bawerk, as if the capital had dropped from heaven. A theory operating with such a restricted concept of capital must be expected to come to grief.

But now we may inquire whether taking into consideration every class of investment directly connected with productive industry, and viewing the process of production as a whole and not by detached portions, a productivity theory may be constructed that can escape the pitfalls in the way of the ordinary productivity theory and meet the demands that must be made upon a complete theory. 
If we view the productive process as a whole, it appears that we have nothing before us but human labor acting upon the physical world. There is no capital as a distinct productive factor. The investment of the capitalist and entrepreneur, the "use of capital" regarded from the point of view of production, is nothing but a special way of applying labor - the "round-about," indirect, capitalistic way. And while nothing but labor is used, nothing is paid out by the entrepreneur in his business, nothing is "invested," that is not looked upon as capital. If, however, we regard the entire process, entrepreneurs as a class appear to pay out nothing but wages. It is only between members of the class of entrepreneurs, between those in control of the different segments of the process of production of any commodity, that payments are made for anything that is not labor. The purchase and sale of "intermediate goods" necessary in making the consumable goods which are the ultimate outcome of an extended process, is a purely intra-class affair. As such these transactions are only a method of dividing up the investment and the gains of capital in an extended process. In a comprehensive view of the process of production, there are, therefore, no separate outlays for labor and for capital. How then can one distinguish a "specific product" of capital? 
How trace any such connection between product and the return of capital as would justify us in formulating a productivity theory?

In the attempt to make out a productive return in some way imputable to capital, one might be disposed to point to the fact that the capitalistic, indirect method of applying labor gives a larger productive result than the noncapitalistic, direct use of labor. This is not saying merely that labor with tools can produce more than labor without tools. It means that a given quantity of labor will yield a larger result if some of it is used to make tools than if all of it were used without such helps. That the productive advantage of the capitalistic process, the surplus of product it can yield above that given by an equal amount of labor used in non-capitalistic ways, is an important source (if not the only one) of the income of capitalist and entrepreneur, is a statement not likely to meet with contradiction. Whether the amount of this surplus can be definitely ascertained or not, whether all of it goes to capitalist and entrepreneur, or whether the laborer may receive a portion of it, whether capitalist and entrepreneur are restricted to it or can derive gains from other sources, it seems pretty certain that such a large part of the income of capital is drawn from this surplus of product, that if there were no such surplus, capitalism as we know it, could not exist. 
The recognition of the superior productive power of the capitalistic process as a condition necessary to the existence of profit and interest, does not, however, give us a complete theory of profit and interest. There remains to be explained the process by which a percentual rate is brought about and of course the explanation may not assume this rate. The timepreference theory would account for the rate by an appeal to subjective factors. The productivity theory, however, or any theory based on objective factors, must show the value of the investment, the "capital" as determined in some way independently of the discounted value of the product. Can any conceivable productivity theory meet these demands?

At this point we need to consider a version of the theory which perhaps may come to be the authoritative one for many who hold the faith. It is suggested by some passages in Böhm-Bawerk's writings and may be picked out in fairly definite form from the eclectic theory of Landry. Its basis is not the productivity of particular concrete capital goods, but rather the productive advantage of an extension of the "production period," or if you will, the productive advantage of a longer process of production as compared with any shorter one. Successive investments taking such a form as to result in extensions of the production period, bring about an increase of return, at least within certain limits, over and above what 
could be produced in a shorter process. If we may suppose different methods of producing the same commodity, some more capitalistic than others, or to put it in other words, if we suppose productive processes of different length in the same industry, the investment necessary to pass from the less to the more capitalistic method, from the shorter to the longer process, may have imputed to itself the increase of product realized.* There remains to be accounted for the persistence of the older and less capitalistic methods, the relatively underequipped establishments existing side by side with the superior. There is to be explained the failure of some of the better equipped even, to reach the maximum of efficient equipment which the technical knowledge of the time seems to make possible. Why does not the most effective form and degree of equipment known become general throughout each industry? The answer given is, "Because of the insufficiency of capital available," capital appearing to mean chiefly the means of supporting labor, in the long drawn out, capitalistic processes of production. Because of this lack of capital,

*The word "method" is used for the sake of brevity. There need not, however, be a distinct difference in general method. The difference thought of is rather in the degree of equipment with some of the results of the earlier stages of a long process, i. e., it is a difference in the length of the "production period" as measured by Bohm-Bawerk (Positive Theory, Book II, Chapter II). When, however, this difference reaches a certain degree, it becomes difficult to think of it as only quantitative and not as a qualitative one, $i$. e., it becomes a difference in method. 
there remain abundant opportunities for gainful extensions of the productive process and the gains must fall to the owners of capital.

This assumption of a normal insufficiency of capital is somewhat open to question. It is in conflict with the obvious redundancy of capital which appears from time to time. If, indeed, Böhm-Bawerk were right in thinking the rate of product capable of indefinite increase through lengthening of the "production period," there never could be capital enough to exploit fully the endless succession of productive opportunitjes. Böhm-Bawerk's idea, however, we have seen is erroneous. ${ }^{*}$ There are limits, perhaps quickly reached, to the productive possibilities of employing additional capital in extending the production period. In consequence it is quite conceivable that in a time of rapid increase of capital, there may be, not only no lack of capital, but an excess. The persistence of relatively ill-equipped establishments and of unexploited opportunities in the face of such abundance of capital, can be explained in large part by reference to factors which economists are wont to group under the title of "friction." Capital is not a perfect fluid inevitably finding its own level and filling every depression. And not all productive opportunities are controlled by men of sufficient ability and credit to command all the capital which might be advantageously employed. A

*See footnote, page 24 . 
plethora of capital may, therefore, obtain, at least, in a temporarily static or unprogressive society. In a dynamic stage of industry, progressive inventions will, for a time, create opportunities in excess of what the capital available can exploit; although, as we have seen in the preceding chapter, the opportunity for large capitalistic gains may rapidly create the necessary supply of capital. A dynamic state appears, therefore, to be a necessary assumption of the productivity theory which we are at present considering. * It is not a theory applicable to static conditions.

The formulation of the productivity theory we are considering, has some points of superiority over that which operates with the notion

*This suggests the theory recently advanced by Schumpeter, some comment on which may be introduced at this point. Accepting Clark's argument that in a static state there is no "waiting," and that the agio theory is, therefore, inapplicable; accepting also Böhm-Bawerk's refutation of the specific productivity theory of interest and of the abstinence theory, Schumpeter concludes that interest on capital in a static society is inexplicable and hence impossible, and that the explanation of the appearance of interest must be sought in dynamic factors. To the present writer a fundamental defect in Schumpeter's views is found in his theory of wages. No static society such as Schumpeter supposes ever existed or could exist, but if it is permissible to the imagination to construct such a state, why not make one in which the unchanging supply of capital (acting as a "wages fund") is not sufficient to raise wages to the full product of labor? In that case there would be interest on capital. However, the concept of an entirely static state is full of pitfalls and had best be avoided by the theorist. It is frequently necessary to think of a particular group of conditions in static terms, and such has long been the practice of economists. But Schumpeter is wrong in thinking that his construction of a complete and entirely static state is a logical continuation of the classical tradition. 
of capital as consisting of instruments of production. In its use of concepts made familiar by Böhm-Bawerk it presents a view of the productive process as a whole instead of viewing it by segments. But on closer examination it appears to be only a different formulation of the theory of marginal productivity. An extension of the productive process means that a larger proportion of the total labor employed is used in the preparatory process of making and perfecting instruments of production. Labor in the later stages will therefore become equipped with more instruments, and the full productive advantage, the greater quantity of consumable goods, resulting from this rearrangement of the proportions of labor employed at the different stages in the production of commodities, will not appear until the additional instruments have been used. Now it shows a better understanding of what is fundamental to attribute the increase of product to the investment making possible an extension of the production period, rather than to the capital goods which are the results of this investment. But it doesn't after all give us an essentially different theory. Like the more familiar formulations of the productivity theory this version also represents the rate of interest as determined by the gains of the additional or marginal increments of investment. And like them it fails to give a satisfactory answer to the question as to what determines the value or price of 
what is invested. Assuming the value of labor, like that of other production goods, to be the discounted value of its product, it assumes what it should explain. Viewing the productive process as a whole it suggests that the only investment made by capitalists as a class is what is advanced to labor in the form of wages.* Now if wages, the price of labor, could be shown to be determined independently of the discounted product of labor, the way would be open to demonstrating an income as a percentual rate of interest upon an independently determined capital value. This way, however, is closed to the productivity theorists by the theory of wages held by them.

It does not appear that any form of productivity theory has as yet been able to account in a satisfactory way for the rate of interest. Yet there must be some truth, or something exercising the attraction of truth, at the bottom

"Böhm-Bawerk includes "uses of land" (Bodennutzungen). There is no "price of the uses of land," that is no rent, at the margin, and following our plan of viewing the problem as that of the division of the marginal product only, we might disregard the difficulties which would arise for the productivity theory from the attempt to include rent in the investment. If rent is paid at the end of the productive process, as a share of the product, it creates no difficulties for the productivity theory. If paid in advance, it supposedly equals the discounted value of the product assigned to it. In that case there enters the illegitimate assumption of a discount rate already established. It may be remarked in this connection that the concept of a price of uses of land, employed by Böhm-Bawerk and Schumpeter, is an unfortunate substitution for the older concept of land rent. It conveys the misleading suggestion that different quantities of uses of a given piece of land may be bought at a given point of time. 
of such persistently recurring ideas as those formulated, in one way or another, in the various productivity theories. Capitalism is more productive than labor not aided by capital. To the writer it appears that the form of productivity theory we have just examined, the theory suggested by BöhmBawerk and Landry, has some elements necessary to a complete explanation of profit and interest, and that with one important modification or addition, it can be converted into, or led over into, the most satisfactory solution of the problem at present attainable by the method of abstraction and general theory. The necessary modification is to be reached by the way of a theory of wages. Before proceeding to the formulation of a theory of profit and interest, it will be well, however, to call to mind just what is the nature of the problem before us. 


\section{CHAPTER VI}

THE ESSENTIALS OF A THEORY OF PROFIT AND INTEREST

To make income appear as interest; it must be expressed as a proportion or percentual rate. Profit of capital too is to be stated as a rate. If it were not calculable in this form, the entrepreneur would not know what to bid in his bargain with the capitalist, and the capitalist would be ignorant of the business value of what he had to offer. The existence of a rate, however, presupposes two values, (I) the income that is calculated as a rate and (2) the capital sum of which the income is to be stated as a percentage. Let the rate be represented by $R$, the net income by $I$, the capital by $\mathrm{C}$. Then

$$
\mathrm{I}=\mathrm{CR}
$$

This equation gives us three quantities of importance in the theory of interest. A fourth significant quantity, the gross income, represented by $I^{\prime}$, is given in the equation

$$
\mathrm{I}^{\prime}=\mathrm{I}+\mathrm{C}
$$

Having four quantities in two equations, it will suffice to know two of the four in order to calculate the others. The theory of interest need not, therefore, explain the quantitative determination of more than two of these quantities. These, however, must be capable of calculation independently of the other two. 
To derive them by assuming one or both of the remaining quantities, and then to turn about and use them in accounting for the latter, would obviously be reasoning in a circle.

None of the theories so far examined has explained, or appears to be justified in assuming as accounted for, more than one quantity. That quantity is $I^{\prime}$, the gross income, if taken in the sense of the product in the shape of consumable goods of a completed process of production. Its amount is explained by reference to the technical conditions of production and its value by the demand of the market. If, however, $\mathrm{I}^{\prime}$ is to include the product of different stages of the process of production, - intermediate or producers' goods, as well as consumers' goods, - it cannot be accounted for without bringing in one of the remaining three quantities.

The productivity theory aims to explain $\mathrm{R}$ by showing the relation between $\mathrm{C}$ and either $I$ or $I^{\prime}$. It must, therefore, account for the value of $\mathrm{C}$, and at that point, as critics have shown, the theory breaks down.

The time-preference and abstinence theories seek the origin of $\mathrm{R}$ in subjective conditions. If successful in this, they would not need $C$ or I to account for R but could, on the contrary, derive $\mathrm{C}$ and $\mathrm{I}$ from the $\mathrm{R}$ which they have explained, and the $I^{\prime}$ which they might legitimately assume as known. If, however, the criticism of these theories presented in Chapters 
III and IV are at all valid, the attempt to derive $\mathrm{R}$ from subjective factors has proved a failure. The time-preference view is false to the psychology of investment and the abstinence theory, while suggesting subjective factors which may have some influence on investment, fails to prove that such factors give a definite quantitative result, or in other words, that they make $R$ just what it is.

If we take any process of production from beginning to end, $\mathrm{I}^{\prime}$, its product in the shape of consumers' goods, may be assumed as known and accounted for. One other quantity must be found. This can not be $R$. The productivity theory makes no effort to show an independent origin of $\mathrm{R}$; the time-preference and abstinence theories have failed in that attempt. It must therefore be I or C. No way has yet been suggested of accounting for I without using either $\mathrm{C}$ or $\mathrm{R}$. The theory of interest must therefore seek to show the quantitative determination of $\mathrm{C}$. No other course appears to be left open.

With $\mathrm{C}$ determined as well as $\mathrm{I}^{\prime}$, the minimum of data needed to account for the rate of profit and interest is given. But $\mathrm{C}$ must be determined independently of I and R. Furthermore, as there appears to be no way of deriving $C$ from I' except by a not permissible introduction of either R or I, we may say that it is a necessity of theory to account for $\mathrm{C}$ without resort to $\mathrm{I}^{\prime}$. Capital (C) as quantitatively determined 
must be accounted for independently of the other three quantities with which the theory of interest and profit has to reckon.

What is this capital (C)? If we view the production of any kind of consumable goods as a whole and disregard its segmentation into particular industries, we see that what entrepreneurs and capitalists as a class invest, is just wages, nothing more. If wages as $\mathrm{C}$ can be shown to be determined independently of the gross income $\left(\mathrm{I}^{\prime}\right)$ of industry, then $\mathrm{I}$, the net return to capital, can be obtained by subtraction from gross income, and $R$ is easily reckoned by the formula $\frac{\mathrm{I}}{\mathrm{C}}$. The theory of interest as we have seen is driven to account for $\mathrm{C}$ independently of the product of industry $\mathrm{I}^{\prime}$ and the rate of interest or profit ( $R$ ). If capital is restricted to so-called "capital goods" this is impossible. The value of a machine, for instance, as has been shown, cannot be obtained without assuming a rate of profit and interest. Nor will the money invested serve the purposes of theory. It is not money, but what can be bought with it that is the source of income. The only way to get an independently determined investment upon which the return obtained can be calculated as a rate, is to view the process of production as a whole. Then it will appear that the investment made by entre- 
preneurs and capitalists is all in the form of wages. $\mathrm{C}$, therefore, consists of the total of wages.

If the above conclusion in regard to the direction in which we must seek for a solution of the problem of the amount and rate of income on capital is correct, it will be necessary to find an explanation of wages apart from the size of the product of the productive process $\left(I^{\prime}\right)$ or the prevailing rate of capitalist return (R). That, however, brings us into conflict with the productivity theory of wages, which in one form or other, commands the adherence of most economists.

Now the theory of a specific product of labor, separable from the specific product of capital, and determining wages, we have already disposed of by implication in our criticism of the specific productivity theory of interest. It is in obvious conflict with the fact that the employer regards the sums paid out in wages as capital on which he must earn interest, at least. He could not afford to pay more than the discounted value of the product to the laborer. The widely accepted theory of wages as determined by the discounted marginal product, however, stands in a much stronger position. A detailed criticism of it will be given in Chapter VIII. This form of the productivity theory has the advantage of not being out of harmony with the conception of the productive process gained when it is viewed 
as a whole. When this view is taken it appears very clearly that we are driven to a choice between two theories of residual income.* One theory would hold the rate of profit to be determined by subjective factors, by calculations of the cost of abstinence or waiting. In that case the wage earner, receiving the product of labor discounted, is the residual claimant. The other would find an independent explanation of wages, in which case profit of capital can be accounted for as residual income. The former alternative is not open to us if our criticism of the time-preference and abstinence theories is valid. There remains, therefore, only the residual claimant theory of profit.

The details of a theory of wages on which this view of profits can be based will be developed in the two following chapters. The remainder of this chapter will be given to an exposition of the theory of profits we have reached on the assumption that the theory of wages necessary to it can be demonstrated. Anticipating a little, however, we may state that the explanation of wages to be given is based, in part, on the idea of a supply price of labor determined chiefly by conditions outside of capitalistic industries and localities. The gains of capital are largely a result of the productive superiority

*Unless with the "bargain theory" of wages, we practically give up the attempt to account for the existing division of the marginal product between capital and labor, and declare it to be simply the somewhat indeterminate outcome of a struggle. 
of the capitalistic method. By using expensive, "roundabout" processes and methods of utilizing natural forces, not accessible to the laborer because of his ignorance and poverty; by organizing, disciplining, and driving laborers to greater effort than they will or can put forth when working by and for themselves, - capitalistic industry produces a surplus, a value in excess of what is paid out in wages. The wages paid constitute the capital invested, if we regard industry as a whole. The surplus product is profit of capital plus land rent. Setting aside rent and differential profit as the excess income of investments receiving more than the marginal return, this surplus, as profit of capital, can be stated as a percentual rate of the sum paid out of wages. How this rate is divided between capitalist and entrepreneur, establishing a rate of interest, as distinct from this rate of profit, we need not consider at present. It is not a problem that presents insuperable difficulties. * The crucial problem is the rate of profit.

This theory of profit makes the productive advantage of the capitalistic process appear as an important source of profit and interest, yet cannot properly be called a productivity theory. The surplus of product left after wages are paid, which constitutes profit, while largely

*A very satisfactory account of how the rate of interest is established can be found in Hadley's Economics, p. $269 \mathrm{ff}$. 
due to the technological advantage of using capital, can in part be traced to other sources. Some of it is due to the knowledge and energy of those organizing industry. Some also to all those forces, whether operating within or without the sphere of capitalism, which make a cheap supply of labor by keeping down the standard of living and narrowing the economic opportunities of non-capitalistic labor.* Nor does it follow that the entire technological advantage will go to capitalist and entrepreneur, and that the laborer may never have a share in it. Some of the surplus may be used to lure labor into the capitalistic system. Some may go to labor when a strong union, seizing a temporary advantage, drives a hard bargain. Some goes to skilled labor which has been reared within capitalistic districts and which outside of capitalistic industries could look for no return whatever.

The title of productivity theory would not fit the views here set forth. Nor would the term exploitation theory be any more appropriate, although it is suggested that interest grows out of a portion of the product of labor withheld from the laborer. The term exploitation carries an ethical connotation which it would have been well to keep out of economic

*Loria and Oppenheimer have especially emphasized conditions of land ownership as a source of capitalistic gain. See a good summary of Loria's writings by Rabbeno in Political Science Quarterly, Vol. VII. Of Oppenheimer's writings, see especially his Theorie der reinen und politischen Ökonomie. 
theory. Whether there is the moral wrong of exploitation at the source of capitalistic income is a question outside of the scope of economic investigation. It is not probable that the purely economic theory of distribution can contribute more than a small part of the data necessary to a judgment upon the present social system as a whole, and of the ethical status of the income of capital in particular. We are taking a small and inadequate view of the problem raised by socialism, if hopes or fears of settling that problem give any bias to our thought in the study of the theory of interest and profit.

It is desirable, therefore, if a name must be given to the theory here set forth, to find a term without ethical flavor. Such a safe, colorless term, one properly applicable, is that of residual-claimant theory. It is the name which has been given to the theory of profit on capital of Ricardo and Marx, with which our theory is in substantial agreement.*

At this point it will be desirable to consider briefly three questions suggestive of objections to the theory here advanced. (I) What is there to prevent excess product due to capital

*See Hollander (The Residual Claimant Theory of Distribution in Quarterly Journal of Economics, February, 1903) who applies the name to the theory of Ricardo. In the third of an interesting series of articles on "Wertrechnung und Preisrechnung im Marxschen System," in the Archiv für Sozialwissenschaft 1907, Bortkiewicz suggests the name Abzugstheorie for the theory of Ricardo and Marx. 
from bringing about a fall of values which would extinguish profit and interest? (2) What keeps labor from demanding and obtaining all that it produces? (3) How is the surplus value growing out of a series of processes, under the control of different entrepreneurs, distributed as a fairly uniform rate to every part of the investment made by each entrepreneur, and not alone to the sums paid out as wages?

To take up the first question: why does not the surplus value including profit and interest disappear in a fall of prices? How can the profit be kept from the "consumer?" There is here suggested the objection sometimes made to the productivity theory of interest, that it does not show how the capitalist can keep his "product of capital" from lowering prices till interest disappears. This apparent difficulty is by some writers made the occasion for bringing in the cost of abstinence as a necessary check upon redundancy of capital and capitalistic production. The objectors, however, fall into the common error of thinking of but one industry at a time. Excess of product in one industry might indeed bring about a "ruinous" fall in value. A general fall of values, however, is impossible.

Moreover the objection that profit and interest will be surrendered to the "consumer" unless production is in some way limited, rests on an erroneous conception of the status of the consumer. When we look at things, not from the 
point of view of a single industry, but of the industrial system as a whole, it is obvious that the "consumers," the purchasing public, are not a class distinct from the "producers," nor an independent factor governing prices. The purchasers or consumers are the capitalists and laborers of the productive process. As long as the laborers do not receive the whole sum of money and credit possessed by capitalist and entrepreneur, as long as the latter retain something for themselves, this something, added to the purchasing power in the hands of the laboring class, will keep the total of prices of commodities above the total paid out as wages. The sum of prices cannot extinguish profit of capital by falling to the sum of the outlays for wages. As long as the capitalist and employer are not obliged to surrender everything to the employe, profit and interest will continue.

But may profit of capital throughout industry as a whole be made to disappear by a rise of wages? This is the second objection our theory must meet. Why does not labor obtain the entire product? As long as the value of the product is in excess of the wages paid, would it not be profitable to employ additional labor? Would not this be kept up until in every industry wages equalled the marginal product, leaving only a differential profit on the more productive investment but no profit or interest at the margin. The adherents of the abstinence or time-preference theories would assert that the 
needs of the marginal saver, the cost of his abstinence or waiting, or the degree of his reluctance to give up present for future goods, would check the upward course of wages. Do these subjective factors act as a check on any forces tending to narrow the rate of profit? And if they do not, what is there to save capitalist income from extinction? In Chapter IV it has been shown how doubtful and uncertain is the influence of subjective factors in checking the fall of profit. It was also shown, however, that, when additional supplies of capital meet a vanishing rate of return, either forces destructive of redundant capital are brought into action, or new opportunities are somehow found for profitable exploitation. 'Does an increasing supply of capital have a tendency to raise wages? Whether it does or not, there are forces sufficient to check an increase of capital leading up to an extinction of profit, - forces so erratic in their operation, however, that it is impossible to predict their course by any simple formula. But the factors determining the scale of wages form the subject matter of the two chapters following this. A full discussion of whether they could threaten profit with extinction would be out of place at this point.

The third difficulty which must be met by the theory here advanced is that. suggested by the question as to how the surplus product growing out of a series of processes under the 
control of different entrepreneurs, is distributed as a fairly uniform rate and assigned to each entrepreneur's investment and, moreover, to every part of it and not alone to the sum paid out as wages. Apparently a rate can be calculated only by the summation of the incomes of all the capitalists and entrepreneurs and the estimation of this sum as a percentage of the total paid out as wages. But how is one to proceed from this rate to a rate assigned to every part of the investment, to machinery and buildings, as well as to the sums paid as wages? As a matter of fact, the rate of total profit is purely theoretical. The gain to capital which arises as a surplus of total product over the total of wages is a quantity not estimated by any one as a percentual rate. It is a quantity, however, for which entrepreneurs engage in a struggle and out of this struggle arises an average rate of profit which coincides with the theoretical rate of total profit.

If the entire process of making any given commodity, including the production of all material and instruments entering into the product, or used up in the process, were controlled by one entrepreneur, - whether an individual, a partnership, or a corporation, - it would be possible to state total returns above wages as a percentual rate upon wages regarded as the investment. Actually the process is divided up among different entrepreneurs, and among these the return in excess of wages, is 
divided roughly according to the extent of their investment. If the entrepreneurs of the earlier stages of the process of production seek unusual gains at the expense of those in the later stages, the latter can threaten to make themselves independent of the former by undertaking to produce for themselves the materials and instruments they may need. Or they can encourage competitors of a more reasonable frame of mind. In like manner the entrepreneurs of the earlier stages can defend themselves against those of the later. Thus, through bargaining and competition, a rate of profit becomes established for any given industry. By movements of capital from one industry to another, the rate is equalized throughout the industrial system. ${ }^{*}$ This equalized or average rate of profit is, of course, only a theoretical approximation to actual conditions, a static goal never fully attained in this dynamic world. The sums invested are given a share in the returns according to the time at which they enter the investment. In other words, the rate assigned makes allowance for the time element, and is calculated and compounded according to a custom established before modern capitalism itself.

The solution of the problem of profit of capital and interest given above, assumes the existence of interest and capitalistic calculation. What

*Compare Ricardo, Principles, Chapter IV, and Marx, Kapital, Vol. III, especially Chapter X. 
the historical origin of interest may have been, how such an income was possible before the modern machinery of production, and why it was estimated and compounded at a time rate, are questions we need not seek to answer. The theory aimed at in all of the foregoing discussion, applies to the modern era alone and may, therefore, assume as given such factors as have been transmitted from pre-capitalistic times. As long as the method of "theory" takes its premises from conditions now open to observation and not from the historical past, it must, of necessity, submit to such limitations. It reveals the forces at work in the present and the conditions of their continuance. It can make no pretense of throwing light on the whole course of the evolution of economic institutions whose birth has preceded our historical era. 


\section{CHAPTER VII}

THE THEORY OF WAGES. THE SUPPLY OF LABOR

Our discussion of the income of capital has led of necessity to the question as to what determines wages. The marginal product of industry is divided between profit and wages. A theory of either of these shares carries, by implication at least, a definite opinion in regard to the determinants of the other. The view of profit and interest as residual, set forth in the preceding chapter, rests distinctly on the assumption that wages are determined independently of the rate of profit and of the value of the product. Obviously the next step in our argument must be to establish a theory of wages in harmony with this assumption. Such a theory, however, is not likely to meet a very ready acceptance unless the, at present widely held, productivity theory of wages can be dislodged. A criticism of this theory will be offered in the next chapter. In passing, however, it should be pointed out that because of the close relation between profit and wages, our criticism of certain theories of interest, if valid, has by implication given a refutation of the productivity theory of wages associated with these theories. If, for instance, there is no specific product imputable to capital, separable from the specific product of labor, then there is no specific product 
of labor. Thus the weakness of the specific productivity theory of interest is also the weakness of the specific productivity theory of wages. Moreover, the impossibility of regarding employers as willing to pay out sums of money for wages upon which they do not earn interest at least; in other words, to pay the full undiscounted product of labor to the laborer, makes the specific productivity theory appear too obviously inadequate to deserve much attention.

A theory much in fashion to-day, is that of wages determined by the discounted marginal product, the rate of discount being fixed by the "rate of time-preference" or the "cost of waiting." But, if we have succeeded in our attempt to show that time-preference or calculation of the cost of waiting, or postponement, or abstinence, or any subjective valuations by whatever name, can create no definite rate of discount, then obviously wages cannot be explained as determined by discounting the product.

In the view of profit of capital as a residual claimant set forth by Ricardo and others, the underlying theory is that of wages determined by the cost of subsistence of the laborer. If this theory of wages were acceptable, our argument would have brought us to the $\mathrm{Ri}$ cardian view of distribution in most of its essential positions. Another basis for a theory of profit as residual, might possibly be found in the bargain theory of wages, the theory 
that wages are the outcome of a contest, of Machtverhältnisse. A discussion of these two theories must be undertaken, but also of those in obvious conflict with the theory of profit and interest for which we are contending. Following the course of historical evolution let us begin with an examination of the subsistence theory.

The argument for this theory was based on Malthusian views in regard to the growth of population. If wages rose above the "natural wage," earlier marriages and a higher birth rate increased the supply of laborers and reduced wages to the old level. If wages fell below the natural wage, postponement of marriage and a lowered birth rate, diminishing the supply of labor, raised wages again.*

But how much was the "natural wage?" It was supposed to give the laborer a living according to the customary standard of his class. How this "standard of living" originated, the classical enconomists did not inquire. It was an historical problem which they were under no necessity of solving. All that was essential to their argument was that the standard should be stable. This implied that in times of falling wages, the standard would not be sacrificed to the desire for marriage; but that in times of rising wages, marriage would be the

*A minor factor was the death rate varying inversely with changes in wages. It makes no difference to the argument to omit its action from consideration. 
first claimant on the increased income. It supposed a great fixity in the manner of living of the working classes in everything except the age of getting married and the consequent eventual size of the family.

Now if the term "natural wage" was to have a definite meaning, it was that of a wage sufficient to maintain at the customary standard a family of a given average size. ${ }^{*}$ As actual wages departed from the natural wage, the standard of comfort was maintained by a variation in the average size of the working class family. Thus except in short periods of transition and adjustment, actual wages would always cover the standard of living. This correspondence between wages and the standard of living could not, however, be regarded as evidence that the standard effectively determined actual wages. Unless one considered results in the long run, the truer view would be that wages on the one hand, determined primarily by "demand," and the standard of living on the other, had no effect on each other, but together determined the average size of workingmen's families. To express the same thought in a different manner, the standard of living maintained itself in the face of fluctuating wages by varying the average size of families. If, however, one looked at the tendencies of a long run, it would appear that these changes

*To be very precise, a given average size and composition, as expenses would vary somewhat according to age and sex. 
in the average size of the family would eventually affect the supply of labor and thus influence the level of wages.

It should be noted, however, that the factor set forth by the classical writers as regulating the supply of labor was obviously extremely slow in its action. It might take fifteen to twenty years for a sufficient number of children to be born and trained to industrial pursuits, to increase effectively the supply of labor; or before the death rate overtaking a diminished birth rate could effectively decrease the supply. Because of this slowness, the regulation of the supply through the growth or decline of the laboring population would bring wages back to the "natural wage," only if disturbances of the actual or "market" wage through fluctuations on the side of "demand" did not occur except at long intervals.

But is there a natural wage? Ricardo defined it as the amount necessary to enable laborers "to subsist and perpetuate their race, without either increase or diminution." Now the entirely stationary wage-earning population supposed by Ricardo, in all probability, never existed. And if population has always either increased or decreased, "natural" wages were never paid. The concept of natural wages, therefore, could at best serve as a means of exposition only, indicating an ideal point of equilibrium towards which the forces making the rate of wages were supposed to be working. 
The slow operation of the factors set forth by the Malthusian argument for the subsistence theory, forms the basis of Marx's criticism of this argument. Holding that there is a decennial cycle of prosperity and crisis, he reasons that long before a rise or fall of wages could have any effect on population the whole scene would be shifted by various phases of the business cycle. * As an objection to the notion that a given natural wage could be brought about primarily by the movements of population, Marx's argument has great force. It does not, however, dispose of the fact that the size of the working population has an effect on wages. Indeed, the further development of Marx's own ideas on wages implies such an effect. Nor does Marx prove that wage fluctuations are of such disconcerting frequency that the movement of population cannot at all be affected by a rise or fall of wages.

An objection to the Malthusian argument for the theory analogous to that presented by Marx, is suggested by the part which immigration plays today in almost all the great industrial districts of the world. Against the vast tide of immigrants, the slow changes caused by fluctuations in the native birth rate seem of very slight significance. It should be remarked,

*Das Kapital, Chapter 23, Section 3. 
however, that at the time the subsistence theory gained its position in orthodox politicaleconomy, this difficulty did not exist

In view of the slowness of the factors described in the classical exposition of the subsistence theory, there was obviously the need of a theory of wages in which the supply of labor should be regarded as practically fixed for the time being - a theory of actual, or "market wages," as distinct from the "natural wages" towards which things tended vaguely in the long run. In such a theory the emphasis would necessarily be on "demand" for labor. That the subsistence theory was not a complete explanation of the rate of wages was clearly recognized by its classical exponents. They supplemented it with the wages-fund theory in which the emphasis was placed on the factor of demand, and which aimed to explain market wages. Thus two theories were held simultaneously. In one, the wages fund theory, the supply of labor was regarded as fixed for the time being. The other, the subsistence theory, we have seen could account for existing wages, only on the assumption that changes in demand occurred at long intervals only, or in other words, that the factor of demand was fixed for long periods of time.

Now it might appear from the trend of our discussion up to this point, that our chief concern must be a theory of "market wages" and of the factor of demand. Though recognizing 
that anything affecting the birth rate would ultimately influence the supply of labor, and therefore, affect wages, it might appear that we are forced to consider such influences so slow in their operation and so disturbed by various factors of more rapid movement, that all attempts to embody them in a general formulation of a wage theory should be given up. Why not rest satisfied with a theory based on the assumption of population as fixed for the time being? It will appear, however, in the further progress of our analysis, that we need not give up trying to make some definite statement in regard to the factor of the supply of labor. Indeed, there is something like a definite supply price of labor, as important in its influence on wages as anything on the side of demand.

But let us return to the subsistence theory. The greatest obstacle to its continued and unquestioned acceptance appeared when it was seen that the standard of living of a large part of the industrial population was rising. If wages had gone downward instead of upward, the standard might have exhibited greater fixity. As it was, the idea began to gain ground that the standard of living was too unstable to be regarded as a regulator of wages. The concept of a natural wage vanished into thin air. Even the more modern idea of supply prices for different quantities of labor, the idea of wages acting as inducement for an increased 
or decreased supply of labor as they rose or fell, became untenable. If, for instance, a rise of wages carried the standard of comfort upward, its ultimate effect might be, by lowering the birth rate, to decrease rather than to increase the working population. It did not appear, however, that the standard is so instantly and extremely variable that there is no standard at all. For the time being there is a standard, though possibly a short-lived one. In the interval before the change to a different level, the standard has some effect on the birth rate and, therefore, ultimately on the supply of labor and its price. But if it affects wages it is also affected by them. The definite, nonreciprocal action on wages assigned to it by the classical school is not perceptible.

But though the subsistence theory of wages, based on the Malthusian argument, became involved in all these difficulties, it does not follow that it was never, at any place, a valid explanation of the facts. Within certain geographical and historical limits, some of its reasoning may be applicable. On the background of modern capitalism, to be sure, with its large fluctuations of employment, its pressing host of immigrants, and the instability of all standards of comfort and discomfort, the Ricardian doctrine of a natural wage looks like some pale, ancestral shade. But it was from a different world that Malthus gathered the evidence for the "principle of population" which was made 
the basis of the theory of natural wages. For most of the people of the eighteenth century there was still the regular routine of agricultural pursuits calling for almost the same number of workers year after year. There was little immigrant labor and the manner of living, consecrated by custom, was almost incapable of variation. In the backward, rural districts of the old world from which today we derive our supply of unskilled laborers, we 'may still see conditions differing but little from those pictured by Malthus. To be sure the portentous fact of emigration has broken into the quiet current of their life. The established standard of living, however, still possesses stability. A temporary fall of income results in emigration and postponement of marriages, a rise, in earlier marriages and a higher birth rate. New commodities enter but slowly into customary use. The luxuries and novelties of the well-to-do are both geographically and socially too remote to lure to a more expensive scale of living. Of course, the subsistence theory may not be applied without qualification to an explanation of the income of the laboring population of these non-capitalistic regions. As already indicated, the theory cannot, in any case, offer a complete explanation of the level of wages. If, however, we had only these old world conditions to consider, the classical 
doctrine of wages adjusted to cost of subsistence might be allowed as a rough approximation of the actual forces at work.

It may be asked, what is the need of any reference to old world conditions? Our concern is with the dividing up of the product of capitalistic industry and, therefore, with the wage level of modern industrial centres only. The reply to be given is that it is a mistake to fix the attention exclusively upon the industrial areas or to think of economic life as all within an isolated, national unit. The conditions of the distant sources of our labor supply cannot be without influence upon industrial wages. We may be sure that an important factor determining wages in all growing industrial centres is found in the terms upon which additional laborers can be secured. But securing additional laborers means attracting increased immigration. The average income of the old world population from which our unskilled laborers are almost entirely drawn may be said, therefore, to constitute part of the supply price of labor for our industries. That much, at least, must be paid - and in order to induce men to immigrate - something more. We may leave open the question as to whether this income determined by pre-capitalistic conditions, is best explained by emphasizing the customary standard of living, or the narrow productive opportunities of these workers. For us the significant fact is that this income plus an 
amount sufficient to act as inducement to emigrate to the regions of modern industry, is the price which must be paid to secure the lower grades of labor for our industries.

For the higher grades there enter other factors, less easily summarized in general formulæ. Often it will be necessary to regard the supply of certain kinds of skilled labor as practically fixed. So far as it is possible to make out a "supply price" for an additional amount of one of the higher grades, it equals the wages of unskilled labor, - determined, as we have seen, in large part by non-capitalistic conditions, - with enough in addition to induce part of the working population to undergo the necessary training, or to bear the expense of educating their children, towards a more specialized or more intelligent type.

The price of unskilled labor, therefore, is fundamental to the determination of the wages of all grades of employment. From the point of view of capitalistic industry it is cost rather than utility that makes the supply price of labor. In other words, the average income set by conditions outside of capitalistic industry enters as an independent factor into the determination of wages paid in capitalistic industries.

If the views set forth above are correct, we may speak of a fairly definite supply price for labor. It varies both with the grade of labor and with locality. At the distant sources of our 
immigrant labor, in the backward, rural districts of the old world, a fairly stable standard of living makes a rise or fall of wages result respectively in an increase or decrease in the rate of growth of the population. Such adjustments of the supply of labor, however, are slow and imperfect. For the areas of capitalistic enterprise, the important factor determining supply of labor is immigration. More or less of immigrant labor can be attracted as wages are raised or lowered.

An important part of the supply price consists of the amount necessary to act as inducement to undergo the expense and hardship of immigration. The supply price of labor will, therefore, tend to vary directly with the distance from the sources of immigrant labor and with the perfection of means of communication. It is often assumed that wide geographical differences in the remuneration of labor are due to corresponding differences in produc-

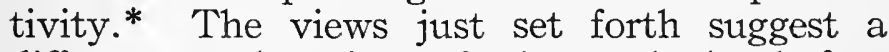
different explanation of the undoubted fact that where wages are high, the productivity of labor is likely to be high. Where, for geographical reasons, the supply price of labor is high, only the most productive uses of labor are profitable to the employer. Where, on the other hand, the supply price is low, the application of successive "doses" of labor may be

*For instance, in discussions of the influence of protective tariffs. 
carried further down the scale of diminishing returns, to a lower margin of productivity.

These propositions in regard to the supply price of labor do not, of course, give a complete explanation of the wage level. An examination of the forces making what is called "demand for labor" must be the next step in our analysis. 


\section{CHAPTER VIII}

THE THEORY OF WAGES. THE DEMAND FOR LABOR

The subsistence theory emphasized factors affecting the supply of labor, but implied the action of both demand and supply as determinants of the price of labor. It was avowedly only a theory of what wages tended to be in the long run. The wages fund theory of the classical economists gave an explanation of what constituted the total demand for labor, but fitted this into a theory of temporary "market wages" only. There was no reference to what made demand in the long run, but obviously this was determined by the accumulation of capital. The relation between total demand for labor and the total working population determined wages for each season of employment, but in the long run these "market wages" or actual scales of payment tended towards the "natural wage."

The wages fund doctrine is an example of the bold collective conceptions of the classical school. Brushing aside the factors entering into all the diverse, particular wage contracts, it gave a view of the wage level as a whole, as though capitalists united as a class dealt with labor as a class. It rested on the thought that so viewed, capitalists and laborers are forced to make an exchange with each other; that 
each party brings just one commodity to this trade, the capitalists their capital, the laborers their labor power, and that each party is obliged to give its entire commodity in exchange for that of the other.

In a rough way these views are true - as true, perhaps, as any general theory in this field ever can be. That the laborers have to sell their commodity on pain of starvation is obvious. To be sure, some of them might emigrate, and the supply of labor might be varied a little by a greater or less number acting as their own employers in agriculture, or as handicraftsmen, or petty shopkeepers. This, however, does not substantially qualify the fact that the larger part of the quantum of labor-power existing at the time being has no "reservation price," that it has to be sold no matter how low the scale of payment.* That despite this cruel necessity not all labor power is sold and that some deteriorates and becomes unsaleable, are qualifications which may fairly be omitted from a general statement of tendencies.

*It must be remembered that at this point we are considering a theory of the forces of the moment only, those making "market wages." In the long run, of course, the classical economists held that cost of subsistence was a reservation price for labor. It may be remarked that they gave no thought to the fact that with a fixed number of laborers employed, there may still be an increase or decrease in average performance, and that efficiency may, therefore, be said to have its reservation price. However, we may assume a standard of efficiency for the time being, not susceptible of rapid change, and, therefore, not giving occasion for much qualification of the statements made above. 
A similar necessity of coming to terms rests on the class of capitalists. They must seek to invest all of their capital as long as there is a prospect of gain. They will not succeed at once in investing all, just as some laborpower fails to find an immediate market. But in order to indicate general tendencies, we are justified in assuming that all of the labor-power and all of the capital are disposed of. The efforts of capitalist and laborer to sell or invest all they have to sell or invest, whether entirely successful or not, make the rates of remuneration what they are. The wages fund theory, like other economic theories, only indicates the point of equilibrium toward which economic forces are working. It deals with the statics of the problem of wages. Friction and "dynamic" changes in the factors assumed may bring it about that the point is never actually reached. We have in consequence to rest satisfied with a formulation of tendencies only.

But if capitalists succeed in investing all of their capital, does that mean that it all goes to pay wages? Must all investment be regarded as fundamentally an exchange between capitalist and laborer? May not the capitalist employer use part of his funds to buy "capital goods" - machines, for instance, - instead of hiring labor? Such objections, of course, occur readily to those who either differentiate wages funds entirely from capital or regard them as only part of capital. If it is permissible to look 
at the problem of wages from the point of view of an individual business or segment of the long productive process, the wages fund doctrine, of course, appears absurd. But the wages fund theory is not one of particular wages, or wages in particular industries, but an attempt to explain the general wage level. It might appear, therefore, that the investment of the class of capitalists as a whole only should be taken into consideration. In that case what one capitalist gives to another, the price paid for a machine, for instance, should be eliminated from consideration. Only that is invested and a source of gain for the capitalist class as a whole, and, therefore, to be regarded as capital, which goes to other classes. Disregarding advance payments of rent, only that which goes to the laborers, i. e., the wages fund is capital. According as it distributed over a large or a small number of laborers, it makes a low or high average of payment. Its division between different groups and grades of labor may change. Buying machines for an industry, for instance, may mean diminishing the number of workers employed and total wages paid in that particular industry while increasing the employment and wages of men engaged in making machines.

Such is the view of the effect of buying additional machinery suggested by the concept of capital for which we have contended. But the matter is not quite so simple. It is begging 
the question to rule out from consideration business outlays other than those for wages, by appealing to a definition of capital which expressly excludes such outlays. The fact that the wages fund alone is a source of gain to capitalists as a class, makes it legitimate in a general theory of distribution, to restrict the term capital to this fund. But the relevant question at this point is whether all of what men accumulate for investment and regard as "capital," ultimately reaches the laborer; or whether part of it may be paid to other parties, to the special group of capitalists who sell machines, for instance, and be consumed by them. The total funds accumulated for use in business must be invested. But must they all go to pay wages; or if not, is there a definite and fixed part of these investment funds destined exclusively for the payment of wages?

When entrepreneurs substitute the purchase of machines for the hiring of labor, they appear to diminish the wages fund. But there must occur an increased employment of men in making machines. Does this mean that the point of application of the wages fund is shifted without change in the size of the fund itself? The prices paid for the machines cover the wages advanced to those who had made them. If these prices included nothing else, that is if employers simply spent their capital for wages and, on the return of an equivalent from the sale of the products, reinvested this and 
again spent it all for wages, - if, in short, there were no interest and profit for the capitalist; then, indeed, all of the investment funds would have to go to the laborers, and the only question would be as to how the total is divided between different groups of workers. But the price of a machine includes profit and interest. Now if, in the language of Böhm-Bawerk, the average production period be lengthened, that is if more of the products of earlier labor be used in the later stages of the production of consumable goods, then there would be an increased outlay not only for labor at the earlier stages but also for profits and interest to the capitalists in charge of these stages. Part of what might have gone to the laborers at the later stages, is by this change of the production period converted into profits for a particular group of capitalists. Of course, coming to the latter as an increase of profit it would probably be invested at once and most of it used in paying wages. If, however, this increment of profit were consumed by its recipients, the total wages fund would be, to that extent, diminished.

This might appear to qualify seriously the validity of the assumption necessary to the wages fund doctrine that there is a definite fund destined for nothing but the payment of wages. If, however, we consider the conditions under which such a contraction of the fund, as has just been suggested, could occur, it will appear that it is still allowable to make the 
assumption of a fairly definite wages fund. The outcome of such an extension of the production period, of the increased material equipment of the later stages, should be an increase of product and profit. What is paid as profits to the capitalists selling machines is an advance payment of their part in the increased profits of the longer productive process. The increment of product of the longer process would, at first, fall into the hands of the employers, but a large part would be added to capital and pass into the hands of the laborer as wages. Thus only in the transition to a longer production period would there be a considerable deduction from the funds destined to be paid out as wages.

Moreover the substitition of machines, for men on a large scale would probably indicate the appearance of inventions of a revolutionary character. Such, of course, appear from time to time but should be regarded as dynamic in character. They may change some of the factors of the problem, such as the size of the investment fund and the proportion of it used in paying wages, and bring about a new resultant average wage. The theory we are considering, however, treats only of the static aspects of the problem of wages. To be sure, BöhmBawerk argues that apart from inventions, that is taking a static point of view, the average production period could be advantageously lengthened, if it were not for the lack of "cap- 
ital." His argument, however, rests on the assertion of the possibility of an indefinite increase of the rate of productivity with every extension of the production period, that is with every increase of material equipment to labor employed. This assertion has been shown in an earlier chapter to be an error.* In times of abundant capital it is likely, therefore, that the productively most advantageous proportion of equipment has been reached by all entrepreneurs except those doomed to fail. 'In other words, for every commodity there is a production period not likely to be greatly changed except by the dynamic factor of invention. When this has been reached, the wages fund may be regarded as a fairly definite proportion of the total funds for investment.

It may be remarked in this connection that Böhm-Bawerk has set forth a theory of general wages which is virtually a wages fund theory, though he would not have it so regarded. It adds an element not developed in the classical doctrine by showing that a given fund may be used to hire labor for longer or shorter periods. Unless the length of the period is established, the average wage remains indeterminate. An increase of capital (of what Böhm-Bawerk calls the "subsistence fund"), instead of giving a corresponding increase of wages to a fixed number of laborers, might be employed in part to lengthen the production period. The problem *See note page 24 . 
of the determination of wages, therefore, becomes that of showing how the efforts of the class of entrepreneurs to secure a maximum gain for themselves, establishes an equilibrium between three factors, - the given subsistence fund, the total number of laborers, and the length of the production period. In developing this idea, Böhm-Bawerk assumes that there is an unlimited possibility of increasing per capita product by lengthening the production period. As has been shown, however, there is a maximum of product attainable. If the supply of capital is such that the point of maximum productivity has been reached, the production period is fixed and the conditions assumed by the older wages fund doctrine prevail - that is, the wages fund and the number of laborers alone determine the level of wages. Under such static conditions an increased investment of capital cannot advantageously make a longer production period. It can only enlarge the total productive enterprise by starting additional business units or enlarging existing ones. Even this is impossible unless the increase of capital is accompanied by an increased supply of labor. If the labor supply increases less rapidly than capital, a rise of the wage level must ensue.

It is a necessary assumption of the wages fund theory that there is a fairly definite fund all of which will be used in the payment of wages. To state it more cautiously, there will be an attempt to use all of it and that means 
paying it out in wages. And the attempt to use all of the fund is an important determinant of average wages. It would be fatal to the theory if it could be shown that the fund was capable of rapid contraction whenever the wage level was not altogether pleasing to capitalists. Of course, the possibility of erratic outside forces suddenly destroying capital or blocking its investment is not relevant. And from any point of view it must be assumed that the wages paid are less than the value of the product turned out. There must be some profit. But we should have to reject the theory if it could be shown that dissatisfaction with the general rate of profit resulted immediately in a contraction of the wages fund, or in other words, that capitalists would hold back from employment any considerable part of their wages fund while there was still any profit to be gained.

Our discussion up to this point has been in defense of the wages fund theory and in support of its assumption of a fund not capable of rapid contraction. We have not, however, as yet examined some of the arguments which, when brought against it in the sixties and seventies of the last century, led to its sudden and all too complete abandonment. The critics of that time aimed to demonstrate a ready expansibility of the total of funds destined for the employment of labor. Little was said about a contractibility of the fund, though 
of course, that quality might be assumed as implied in its expansibility. The turn the discussion took was, no doubt, the result of the use which had been made of the theory by opponents of trade unionism. Could an organized group of laborers get higher wages without a corresponding reduction of the remuneration of other workingmen, or was the total which might be paid to the laboring classes rigidly limited? That was the question upon which all arguments tended to converge.

Unfortunately the attacks upon the wages fund theory were based on a misconception, though a pardonable one, in view of the carelessness with which the theory was usually formulated.* The fund was thought of as money, not as real income; the wages paid as money wages, not as real wages. Viewed thus it was readily seen that credit currency added an elastic element to the fund. Of course credit is somewhat limited by the quantity of cash underlying it. Beyond a certain point further expansion is impossible unless all considerations of safety are thrown to the wind. It would take us too far afield to consider all the conditions of credit expansion and contraction. Only in so far as the wage level is concerned with such fluctuation is the matter at all relevant to our discussion. Other factors, such as speculation and political rumor, epidemics of optimism or depression, perhaps *Taussig, Wages and Capital, Chapter XII. 
most of the forces determining the degree of credit expansion, must be regarded as disturbing outsiders by the theory of wages. The thought of these forces suggests how inadequately the confused and shifting reality is described by general theory and should teach caution in the application of abstract doctrine to concrete problems. But if general theory is at all permissible, then the theorist is warranted in disregarding such disturbing factors and proceeding as if they did not exist. One of the traditional and necessary methods of economic theory is to disregard the existence of a fluctuating supply of money and credit, and to fasten the attention on real income only.

Now what of the wages fund when thought of as real income, as a stock of subsistence or consumers' goods such as laborers could consume? This evidently at any particular time is very little subject to possible increase. If the wages fund theory be thought of as applying only to the market wages of the moment, or of a short season, it is obviously right in its assumption of a predetermined, possible total of wages. If, for instance, an aggressive trade-unionism could force an increase of money wages, there would, for a time, be no corresponding or considerable rise of real wages. If the increased funds needed to pay higher wages were made possible by an expansion of credit, the money and credit left to the class of employers generally for their personal use 
would not be diminished.* In any case, the capitalist and employing classes would not diminish their consumption of necessaries but, if any economy became necessary, would exercise it by a decreased purchase of luxuries. With an increasing money demand for necessaries from the laboring class and no falling off of demand from other classes, prices of necessaries would rise and real wages to that extent would fail to increase. It appears, therefore, that if only the immediate results of a general rise of money wages, such as we have supposed, were to be considered, there would be no sufficient reason for calling the wages fund doctrine into question.

If, however, a longer period of time be taken into view, it will appear that the greater profits gained by producers of necessaries would lead to a shifting of capital from the production of luxuries to that of necessaries and then the higher level of money wages, if still maintained, would mean a higher average of real wages. The higher scale of payment for labor would correspond to a larger wages fund but the increase of the fund would appear as the effect, and not as the cause, of the higher level of wages. Capital funds used to raise wages would have been created by credit expansion. That part of the real income of the capitalist class consisting of luxuries would have been diminished. But all this can be thought of as happen-

*Such aggressive and successful unionism, however, might cause a shrinkage of credit. 
ing only on the assumption that capitalists as a whole do not increase the quantity of money income spent for consumers' goods, or in other words, that they are content to consume fewer goods while saving as large a money fund for investment as before. Unless there is as much saved as before, capital and the wages fund will be diminished, and the general rise of wages will have been but a temporary one.

With a very thrifty capitalist class, determined never to lessen its annual saving, a general rise of wages at the expense of profit and of the current consumption of the rich, is conceivable. In a theoretical discussion it may be given some weight. But it should be noted that if this constitutes an objection to the wages fund theory, it is one of which most of the critics of that theory are debarred from making use. Holding, as they do, some form of the abstinence theory, they should argue that no permanent increase of the wages fund at the expense of profit and interest is possible.

The theory which most gains support from the possibility of an increase of the total of real wages through aggressive labor organization is that which may be called the "bargain theory" - the theory that the respective shares of capitalist and laborer depend on the outcome of a struggle between them. That this theory emphasizes an important factor in the making of actual wage scales, no one conversant with 
the facts would deny. Whatever general theory of wages we come to accept, we must give some recognition to this factor, at least as supplementing the main propositions of our theory. The present writer would hold, however, that the statement that wages are determined by a struggle or bargain, - the outcome of which is largely decided by the relative aggressiveness and obstinacy of the contending parties, while true, does not carry analysis as far as it should be carried. Our theory should aim to note the effect of the resources and strategic positions of both parties on the issue of the struggle. Without such further development of the analysis, the positive contribution of the theory would be little more than a truism, while its negative implication that there is nothing more to be said, would be an evasion of all the difficulties of the problem.

As our discussion has shown, the account given by the wages fund theory of how the general scale of wages is made, fails to allow for many disturbing factors. It is a very abstract doctrine and would need to be supplemented and qualified extensively before it could be regarded as anything but a very rough approximation to reality. Why give it any thought at all if it falls so far short of giving a definite and accurate picture of industrial facts? The answer to this objection is that the wages fund theory gives what no other theory has given or can give - an explanation of the 
general wage level as distinguished from comparative or particular wages. It is analogous to the so-called "quantity theory" of money or theory of the general price level, and as necessary to the explanation of actual wages as the quantity theory is to that of actual prices. The theory of particular or comparative wages, like the theory of relative prices of commodities, or, as it is ordinarily called, the theory of "value," presupposes a general level. Both of these theories of relative magnitude must assume a given fund or flow, the one a wages fund, the other a given quantum of money and credit. The problem in both cases is how the fund is divided up between particular values or prices. For the purposes of a general theory of distribution, however, we need to explain the absolute height of wages, not the comparative scale of payment of different classes of labor. In order to explain how the marginal product is divided between capital and labor, it is necessary to show not why one set of laborers get more than another but what determines either the average or the total of wages. Only on that basis can the share going to capital be accounted for.

No theory other than that of the wages fund can properly be called a theory of general wages or of the general wage level.

The subsistence theory, though contributing to the explanation of both general and relative wages, is confessedly incomplete and can serve, at best, 
only as part of a complete explanation. The productivity theory, practically the only wage theory to have gained general acceptance, though professing to explain general wages, has unconsciously applied a method of reasoning permissible only to an explanation of particular wages. This aspect of current speculation on wages, and the productivity theory in general, must now be subjected to a critical examination.

Although some assumptions in regard to the supply of labor must be pre-supposed, the productivity theory in its usual formulation is devoted entirely to an analysis of the forces on the side of demand. This one-sided emphasis has doubtless been favored by the Austrian theory of value with its analysis of demand as varying with the utility and price of the commodity demanded. Applied with great success to the elucidation of the value of consumers' goods, this theory of value was at once extended to producers' goods including labor. No questions were raised as to whether demand for labor might not differ radically from demand for consumers' goods. Labor was described as subject to a law of diminishing productivity homologous with the diminishing utility of the unit of an increasing quantity of a consumer's good, and its market value as determined by the utility, that is the productivity, of the marginal unit, to the buyer.

Now this description of demand for labor as of altogether the same nature as that for 
consumable commodities, leads to an erroneous conception of the demand as almost indefinitely extensible. Demand for a consumption good means the offer of a part only of the purchasing power in the hands of the consumer, the total being distributed among a large number of consumable commodities. Demand for any of these goods can be almost indefinitely increased by abstaining from or diminishing the purchase of other goods. If good A rises in utility as compared with $B, C$ and $D$, the demand for it increases while that for B, C and $D$ falls off. Demand for labor, viewing it collectively and not from the point of view of one industry or of a single industrial establishment, is limited by the total of funds destined for the payment of wages. These funds, however, instead of being assigned to the purchase of a vast variety of things, as are consumers' funds, are intended for the purchase of labor alone. There is no choice between different goods with the possibility of increasing demand for any of them by withdrawing funds from the purchase of the others. Entrepreneurs may choose between the production of a great diversity of goods but whatever their choice, it involves the purchase of labor, the universal requisite of the productive process. In the use of the wages fund they have no choice between different things but only between different uses of the same thing. 
In short, there is a fund all of which must be invested and the size of which is an important determinant of the level of prices paid for labor. It is distributed as wages among different grades of work in such manner as to tend towards an equality in the marginal rate of profit. Such a distribution of the fund makes the wages of different kinds of labor vary according to their marginal productivity. But it would be an error to leap to the conclusion that, because comparative wages are graded according to productivity, wages are equal to the marginal product of labor (or the marginal product discounted) and that productivity directly determines the absolute as well as the relative scale of payment.* Productivity may be appealed to for the purpose of explaining comparative rates of remuneration only. As a theory of relative wages, the productivity theory may be accepted as, at least, a fairly satisfactory partial explanation of existing wage scales. Its pretense to a valid explanation of general wages, however, must be rejected. The absolute scale of payment, the general level, can be explained only by a reference to the total of purchasing power directed to the employment of labor.

This brings us back to the wages fund theory. We may regret that it seems vague and excessively abstract, - that only by admitting exten-

*This is the error of a considerable part of the attempted statistical verification of the productivity theory by Professor Moore (Laws of Wages, especially in Chapters IV and VI). 
sive qualifications and exceptions, it can be made to appear as an approximately accurate picture of reality. The aim of economic thought, however, should be to specify and formulate as accurately as possible the various qualifying propositions which are to be made, but to treat these as developments or modifications of the wages fund doctrine, not as grounds for rejecting it in toto. The attitude of a large number of economists towards the quantity theory of money might well indicate the treatment which should have been, but was not, accorded to the wages fund doctrine. Various efforts at precise statement of all the factors determining the general price level have given us something much more complicated and perplexing than the bold and crude quantity theory of an earlier time. But for all these developments of the theory, there is, on the whole, little disposition to deny that the existing quantum of money is one of the most important factors in making the scale of prices, and that the quantity theory needs to be perfected, not rejected.

The objections raised above to the productivity theory may be made somewhat clearer by diagrams. These, it may be remarked, will aid us in our constructive as well as in our critical task. In Figure I a fixed supply of labor $(a b)$ is assumed, a condition conceivable as true for short periods; in. Figure II a variable supply with an increasing supply price 
represented by an ascending supply curve. Since the productivity theory regards wages as determined by marginal productivity and the location of the margin depends on the number of laborers employed, some assumptions must be made in regard to supply. The two most probable cases are given and they are not such as could in reason be objected to by adherents of the productivity theory. To simplify the problem it is assumed that there is only one grade of labor. As usual, distance along the abscissa or base line represents supply or numbers of laborers. The distance of points on the curve ec from the base line represents productivity.

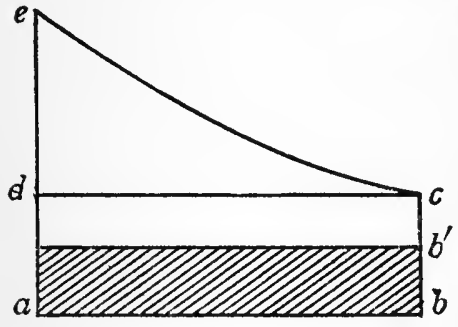

Figure I

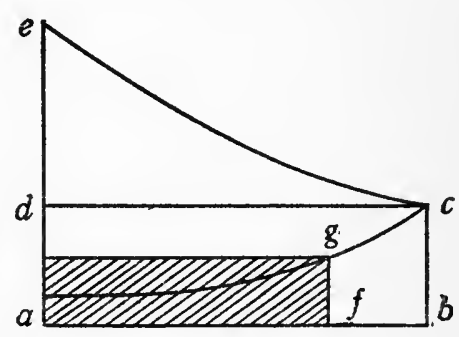

Figure II

Now the productivity theorist would assume that the productivity curve $e c$ may be regarded as a demand curve, representing what employers could pay without loss for different quantities of labor. Under the given conditions of supply they would hold that the price per unit of labor 
would come to equal $b c .^{*}$ But at this point there has crept in the common error that what is possible for one or for a few, is possible for all. An individual employer could pay labor what it produces at the margin (discounted). If his capital was insufficient for this outlay, he could borrow. But the totality of employers could not do this unless the total funds available for the payment of wages equalled marginal product per unit of labor multiplied by the whole number of units employed. In other words the collective wages fund would need to be equal to what is represented by the rectangle $a b c d$ in each diagram. If it were less than this, - if, for instance, it equalled the shaded portion of each diagram, the rate of payment per unit of labor would be indicated by the width of this shaded strip ( $b b^{\prime}$ in Figure I, $f g$ in Figure II). It could not be more than that but would tend to equal all of it.

There is an assumption underlying the productivity theory that wages are paid out of current product; in other words, that the labor of a given week or month is paid out of the product of that week or month. If that assumption were valid, labor's productivity would create the fund out of which it is paid *If we assume that employers would not in any case pay more than the discounted value of the product as wages, the curve $e c$ could be taken to represent discounted value of product. If it represents full value of product, then the wages per unit of labor would be something less than $c b$, and in the case illustrated by Figure II something less than $a b$ of labor would be employed. 
and it would be quite possible to pay labor the full equivalent of its product. But if we look, not at the money funds involved, but at real income, it is obvious that the larger part of the current product consists of unfinished goods, or what Böhm-Bawerk would call "future goods;" and that the consumable wealth of which the real wages of labor consist is, for the most part, the product of labor performed weeks or months ago. The notion that wages could be paid out of current product grew in part out of the onslaught made on a misunderstood wages fund doctrine. The misconception, already referred to in this chapter, of the wages fund as consisting of money or a sum of value expressed in terms of money, suggested that by means of credit the cash proceeds from the sale of current product could be anticipated and used to pay current wages. With less anxiety to have done with the wages fund theory, and a clearer general view of the production and distribution of real as distinguished from money income, of the relation of past to present and future in the continuous flow of products, economic theory might have kept a better perspective and a stronger grasp on the fundamental factors.

Confusion also grew out of the unfortunate tendency to look at things too exclusively from the point of view of an individual employer or business. It brought into the mental foreground the individual employer's estimate of 
what wages he could pay as dependent on the anticipated value of the product, but failed to place in strong relief the important fact that collectively capitalists and employers. could not or would not advance in wages more than what they had saved out of past product and destined for investment.

Now let us return to the consideration of our diagrams in order to examine certain objections which might occur to the reader. The difference between the wage and the marginal product constitutes the profit of capital, equal in Figure I to $c b^{\prime}$ and in Figure II to the extension of $\mathrm{fg}$ necessary to reach the curve $e c{ }^{*}$ The rate of profit as indicated in Figure I would be $\frac{c b^{\prime}}{b^{\prime} b}$. Owing to the mobility of capital, always cheerfully taken for granted in economic theory, there would be a tendency towards the same marginal rate throughout the entire industrial field, and wages everywhere would tend to equal the marginal product discounted by the prevailing rate of profit.

As a statement of what wages equal, of the amount of wages, this is in agreement with the productivity theory. Not, however, as a formulation of the process by which wages are determined. Our argument shows wages to be determined, not by the productivity of labor

*Assuming that the curve $e c$ represents the full, not a discounted, value of the product - an assumption we make from this point on. 
and an independently established rate of discount, as the productivity theorist would hold, but by the wages fund and the number of laborers, under the conditions given in Figure I; and by the wages fund and the supply prices of labor, under the conditions of Figure II. Profit is shown to be a residual left after wages are paid, and the rate of profit the result, and not a cause, of the scale of wages.

Adherents of the abstinence and time-preference theories, however,' would hold that the prevailing rate of profit (at least under static conditions) is a necessary rate determined by cost of abstinence or waiting, or by the rate of time-preference or something of that sort. If the rate of profit were more than this, they might argue, there would be an increase of capital, that is, of the wages fund, and a consequent rise of wages until the diminished rate of profit was no longer sufficient to cause any further increase of capital. Then wages would be equal to marginal product discounted according to an independently determined rate of discount (a rate determined by subjective factors). Product and the rate of discount would appear to be the two determinants of wages and we should apparently have reached the productivity theory of wages now most in favor. It should be noted, however, that the degree of marginal productivity of labor is not, in this way, proved to be the direct and immediate determinant of wages which the prevailing 
theory seems to consider it, but acts through the amount of accumulation of capital which it makes possible. If, for instance, there were a general increase of productive power - which could be represented diagrammatically by a productivity curve drawn at a greater distance from the horizontal base line - wages would not rise until the higher profits had resulted in an increase of capital with which to pay wages.

The strongest objection, however, to regarding wages as determined by the discounted marginal product, is the consideration that the rate of discount cannot enter into the determination of wages as an independent factor but is itself determined by the prevailing price of labor. It is not true that capital must grow until there results a necessary rate of profit which makes further increase of capital impossible. There is probably no rate so small as to stop altogether the further growth of capital. The largest accumulations are made out of the differential gains of earlier, or intramarginal investments, and are not much affected by the decreasing rate of gain left to additional supplies of capital. Some saving would occur if there were no interest or profit at all, and capital once accumulated is not willingly consumed. In any case, as shown in the chapter on the abstinence theory, the great forces determining the supply of capital and thereby the marginal rate of return, have very little connection with the dubious 
and uncertain subjective factors emphasized by the abstinence and time-preference theories.

No general and simple explanation of what makes the total of capital or of the wages fund is possible. The theory of distribution, therefore, must rest satisfied to assume the given amount of capital as one of its data. As to wages, we may say that the wages fund and the factors regulating the supply of labor are the chief determinants. Productivity plays no part except for its permissive influence on the accumulation of capital. Marginal productivity has but a small share in this indirect influence on wages because most capital is accumulated out of earlier or intramarginal investments. As to the rate of discount, that cannot be thought of as determined independently of wages. Whatever tenuous connection may exist between it and the subjective conditions of saver and investor, its most important direct determinant is the wage level. It is an effect, not a cause of the scale of remuneration for labor.

As an explanation of general wages the productivity theory should be unreservedly rejected. It has the fundamental defect, as we have seen, of treating demand for labor as homologous with demand for particular consumers' goods. As a theory of the comparative scale of payment of different employments and grades of labor, however, it is entitled to consideration. Possibly the failure of the classical school to set forth clearly the part which 
relative productivity plays in grading particular wages, may be one reason why the factor of productivity in the end was assigned a part of greater importance than is properly due to it in the theory of both general and particular wages. That the wages fund theory, being an explanation of average wages or the general wage level only, left unexplained the difference in payment between various occupations, was obvious enough to the classical writers. Unfortunately, however, their treatment of particular wages, a problem of inferior theoretical interest, was somewhat perfunctory, and was likely to be no more than a repetition of some observations made by Adam Smith.* Meanwhile superficial and optimistic impressions of the effect of increasing productivity on the earnings of labor, together with the shifting of the view point of economic reasoning by the so-called Austrian school, have given the productivity theory a position of unmerited security.

Of course it has not altogether escaped the fate of all economic theories of being called into question and denounced as fallacious. The usual point of attack, however, has not been that chosen in the preceding pages, but one suggested by the apparent practical difficulties of ascertaining marginal productivity.*

*Canaan, Production and Distribution, 1776-1848, p. 364.

** See especially Arturo Labriola, Distribuzione del dividendo e produttivita marginali, - Cornelissen, Theorie du salaire, and two articles by Richard Schüller in the Archiv für Sozialwissenshaft, July and November, 1911. Schüller's discussion 
Can and does an employer estimate the marginal productivity of labor, either of that which he employs or of labor in general? It must be confessed that the problem looks somewhat puzzling. What, for instance, is the size of the marginal unit? Is it one man or a group of men? The increment of product due to the last of one hundred men taken on, would be less that the average product per man of the group of hundred men. How can one know what value to impute to each of several grades of labor associated in varying proportions in the production of different commodities and in different industries? The doctors disagree in regard to the laws of "imputation." But even if we may accept one of the formulations offered, does it not require the eye of faith to detect the operation of any such law in the actual world? Does not the fact that the employer usually estimates, not the product of the individual laborer or of a group of laborers, but what he calls his "labor cost," make the utilitarian calculus applied to the purchase of labor appear somewhat unreal?

However, labor cost is a function of productivity, and thus indirectly the productivity of labor enters into the employer's estimates of the advantage of hiring labor. In fact all

is especially suggestive because of its concrete and painstaking character. The best known criticism in the English language is probably that by Hobson. See "The Industrial System," p. $112 \mathrm{ff}$. See also an article by W. M. Adriance in the Quarterly Journal of Economics, November, 1904. 
of the difficulties raised by the critics only indicate that in the real world, in place of the precise calculations attributed to the employer by the productivity theory, we find only guess work, and rough approximations of what is profitable. It is not proved that as a formulation of tendencies, of points of equilibrium towards which economic forces work, the calculus of the productivity theory may not be accepted. The real weakness of that theory lies, as we have seen, in the assumption that employers are able and somehow willing to pay either the full value of the marginal product, or this value discounted according to some independently established rate of discount. As an account of what makes the comparative scales of remuneration for labor the theory may pass muster. It does not give an acceptable explanation of the absolute earnings of labor, that is of the general level or average of wages.

This concludes our critical examination of wage theories. Its primary purpose was constructive, and to the attentive reader the positive results are already apparent. Stated briefly the theory to which our discussion has led us, is the wages fund doctrine modified by the conception of a flexible supply of labor with a gradually rising scale of supply prices. The assumption of a temporarily fixed number of laborers made by the classical exponents of the wages fund theory, is no longer tenable, 
because of the part played by immigration in the labor markets of all the great industrial areas. The conditions determining wages today are those indicated by Figure II (Page I48). If the lower curve be taken to indicate the supply prices of labor, rising as the quantity of labor is to be increased, and determined chiefly by conditions outside of the capitalistic regions of the world and by the expenses and hardships of emigration - then an increasing wages fund will be divided, not among a stationary number of workers, but among a supply of laborers increased by immigration.

For the lowest grades of unskilled labor, the prices necessary to attract an increasing number probably rise very slowly. The supply curve might properly be drawn so as to run almost parallel with the horizontal base line for a large part of its course. In that case, the supply price would be the chief determinant of wages and an increasing wages fund would result in an increased number of employes in capitalistic industry rather than in a rise of wages. At some point, however, the curve would begin to turn upwards. Our simplest formula must be that the size of the wages fund, or the supply of capital as we conceive it, together with the supply prices of different quantities of labor, determine the general level of wages. 


\section{CHAPTER IX}

\section{CONCLUSION}

To gather up the results of our inquiry, the outline of the problem of distribution given in Chapter I may be recalled. The first stage in the analysis was that of the division of product between landowner and entrepreneur. It was pointed out that where there is product in excess of the marginal rate of productivity, this surplus must fall to the landowner, - unless, as the result of superior luck and ability, it takes the form of a differential profit. The second stage of the problem was the determination of the rate of profit, profit including both the income of the entrepreneur (exclusive of any differential gain he may obtain) and that of the capitalist. This rate of profit, however, depends on the division of the marginal product between entrepreneur and laborer, and the problem, therefore, becomes that of finding both a theory of profit and of wages. The character and the terms of the division between capital and labor constitute the most controversial matter in the whole theory of distribution. That, however, it is a question of dividing a marginal product, the margin being thought of as both an intensive and an extensive land 
margin, has come very near being generally accepted.*

There are, however, certain ideas which have obtained some currency, but which cannot be fitted into this formulation of the problem, and to these we must now advert for a moment. First, we may take note of a disposition to bring land under the concept of capital, making rent appear as a part of the share known as interest. The objection to be made to this conception is that the total supply of land cannot be increased by saving, or indeed, by any practicable means. As the amount of capital is obviously a determinant of the rate of interest, and in all of its forms other than that of land, can be increased by saving, land, though defined as capital, is left standing outside of the formulation of the important factors determining the income of capital. Additional reasons for declining to subsume land under capital can be found in all the considerations advanced in favor of viewing capital as subsistence advanced to labor.

We may note next the theory which, proceeding apparently on the assumption that land is variable in quantity, regards its rate of return as determined by the specific product

${ }^{*}$ We need not consider at length the views of those who deny the existence of no-rent land. Provided rent as a return above that on an intensive margin is recognized, that is provided the concept of a margin is accepted, there is no substantial departure from the formulation of the problem of distribution upon which our discussion is based. 
of its marginal increment. It is not opposed to the conception of land rent as a differential gain, but refuses to consider this differential character as anything distinctive. Wages and interest, it is argued, may also be viewed as of the nature of "rents." Add successive "doses" of any of the three factors of production, - land, labor, and capital - to a fixed quantum of the other two. Its rate of return will then be established by the addition to total product made by the last dose, while the differential or excess of the earlier or intra-marginal doses, falls as a "rent" to the other two factors, those thought of as fixed for the time being, and as being dosed by the factor in question. Each share in distribution can thus be made to appear both as a marginal return and as a rent.

This "law of the three rents" is, of course, a complicated form of specific productivity theory, and the difficulty already confronting this theory, of demonstrating a specific product for labor and one for capital, is greatly augmented when it becomes necessary to impute something to a third factor.* All the objections which may be made to the specific productivity theory may be made against this variant of the theory. Furthermore, as land is often fixed

*To add a fourth factor, the services of the entrepreneur, and to think of this as applied in doses and rewarded according to its marginal productivity, does not increase the difficulties of an already overtaxed theory of imputation, but is open to other objections. See Edgeworth, "The Theory of Distribution," Quarterly Journal of Economics, February, 1904. 
in quantity and almost never capable of considerable increase, except in the form of norent land, the variability of this "factor of production" assumed by the "law of the three rents," is in conflict with facts which the economists may not disregard. Of course, a particular establishment or industry may secure additional amounts of rent-bearing land. It can do this if it can extract a larger return from the increments of land in question that was obtained in the enterprises from which the land was withdrawn. In other words, advantageous rearrangements of productive forces are possible. Such changes, however, have nothing to do with the shifting of the entire productive margin which the specific productivity theory pictures as resulting from increased or decreased supply of a factor of production. Unless the total supply of rent bearing land is capable of considerable increase, the dosing principle of determining a specific rate of return is not applicable to land. The total supply being practically fixed, the return to the landowner must necessarily take the form of a differential gain, of a product in excess of that resulting from the marginal investment of the variable factors of production. It is only by falling into the all too common vice of regarding the problem of industry from the point of view of one particular business unit, that one can reach the mystic doctrine of the Trinity of Rents. 
To return to our fundamental assumption that it is a marginal product which is to be divided between capital and labor, we found that the various attempts at a solution of this controversial problem, may be grouped under three heads. In other words, three methods have been tried in the attempt to account for the terms of the division of product between capital and labor. First, an independent explanation of one share, either wages or profit, the other being treated as a residual. Second, an independent explanation of each, but the two covering the entire marginal product - the productivity theory. Third, the assertion that the division of the product between labor and capital is the outcome of a struggle - the bargain theory.

Commenting on these in reversed order, we may say that the bargain theory virtually gives up the problem. There is a struggle between employer and laborer, and the comparative aggressiveness and obstinacy of the contestants may largely determine the outcome. The problem for the economist, however, is to define the strategic points on which the contestants base their demands. What alternative has each party in mind when refusing the terms of the other? To call the process of distribution a bargain or a struggle may be unobjectionable terminology, but does not explain its results. 
The second of the three methods of explaining distribution, the productivity theory, is open to various objections which need not be repeated at this point. There is left to us, therefore, only the method of proving either the laborer, or the employer to be the residual claimant. This is impossible in the case of the laborer because the return to capitalist and employer cannot be explained independently of the wage earner's share. The time-preference and abstinence theories cannot account for the rate of return for capital except by imposing a fiction on our minds. There remains, therefore, as the only apparent solution, the demonstration of the scale of wages as independent of the size of the product and of the share going to capital. The explanation of wages propounded in the chapter preceding this, the wages fund theory supplemented by a theory of the supply price of labor, satisfies these requirements and makes it possible to represent profit of capital as a residual income.

The conclusions reached carry us back to doctrines of the classical school. They include the classical concept of profit of capital, in place of the later notion of profit and interest as independent shares; a residual claimant theory of this profit not differing greatly from Ricardo's; and the wages fund theory.

It would, of course, be absurd to insist that the last word on all questions of distribution 
is to be found in the pages of the classical school. Much remains to be corrected or elaborated. But the strategic points of attack on fundamental problems were more clearly perceived by Ricardo and his generation than by the majority of their successors. Not given to academic refinements and subtleties, nor led by radical attacks on property to bend scientific inquiry in the direction of an apologetic of capitalism, their thought moved directly and with single aim upon the significant and fundamental features of the industrial system before them. So far as later developments shift the point of view which must be taken by the theory of distribution, the most significant is the large international movement of capital and labor. The part played by immigrant workers in the advanced industrial areas of today makes it necessary to look beyond the narrow national boundaries of the labor market as conceived by the earlier economists. In our theory of the supply price of labor, recognition has been given to these changed conditions. Other products of economic evolution it has not been necessary to examine. The growth of corporations and the increasing complexity of what Veblen would group as "pecuniary employments" have opened fields for investigation scarcely thought of by the classical economists. The analysis of these developments, however, is not an essential part of the "first approximation," the general 
and fundamental theory aimed at in the preceding pages. For the same reason we may decline to discuss the problem of monopoly gains. In the search for a satisfactory fundamental theory without which the details of an inquiry into the capitalistic processes of these latter days are without meaning, the classical thinkers are still our best guides. The very fact that they are free from the perplexities of later developments in theory and practice, makes them a valuable propaedeutic to the study of the problems of our time. But this praise is only for their scientific work, their unbiased analysis of things as they are. Their political ideals and attitude towards social reform have less significance to our generation and, in any case, are irrelevant to the present inquiry.

The considerations which have led us to reject a large part of the fruits of more recent theory, are stated at length in the critical passages of the preceding chapters. It will not be necessary to recapitulate them at this point. Let us rather take note of certain general tendencies which manifest themselves in almost all of the errors into which modern theory has fallen.

First, there is the excessive rationalism of the utilitarian calculus, whose pedigree may be traced to Bentham, but whose greatest vogue has come through the influence of the so-called Austrian school. It culminates in the 
time-preference theory and in some of its phases is not free from the suspicion of an apologetical Tendenz. As we have seen, it attributes to savers and investors, feats of calculation of subjective costs and gains which are utterly impossible to mortal man. A psychological turn of very questionable advantage was thus given to the theory of distribution. It seems indeed doubtful whether psychology will ever make a positive contribution to the explanation of how the real income of society is distributed. In any case, the application of a crude, hedonistic psychology to the problem was a misfortune.

Another unfortunate tendency in modern economics is the consideration of the problem of distribution as essentially included in the general theory of value. There are, of course, analogies between the purchase and sale of consumers' goods (the proper theme of the theory of value in economic literature) and the purchase and sale of the services of the "factors of production." But the problem in the two cases is not identical. To the theory of value, commodities appear as competing for the consumer's favor. Even monopoly products compete because the competition referred to is not that between different sellers of the same commodity, but that between different commodities. The problem of value, in other words, is that of the relative prices of goods, of the proportionate amounts of money and 
credit in the hands of the consumers assigned to the purchase of each commodity.

Now can this way of looking at the matter explain the remuneration of the factors of production? In trying to develop the analogy the entrepreneur must evidently be assigned the role played by the consumer in the theory of value. Can he choose, as the productivity theories represent him, between different "factors of production;" as the consumer chooses between different consumable goods? If, for the sake of argument, we accept the idea of capital as consisting of "intermediate goods," we have three factors of production which the entrepreneur may purchase.* $\mathrm{He}$ needs all three, though the proportions in which he takes them might vary. So far the analogy holds between demand for factors of production and that for consumers' goods, though there are only three of these so-called factors, while consumable goods are numbered by the thousand. When, however, we look at the side of supply, important differences appear. If any factor is insufficiently rewarded it cannot change into some better remunerated factor. If, on

*The problem becomes very perplexing when the entrepreneur's function is represented as a fourth factor of production. It is something not purchased by the entrepreneur but by the consumers of the products of industry, and, therefore, does not compete with the other three factors for the favor of the same set of possible purchasers. 
the contrary, commodity A cannot command a satisfactory price, its producers can turn to the production of commodities $\mathrm{B}, \mathrm{C}$, or $\mathrm{D}$. The insufficiently remunerated factor of production may not even have its supply diminished. We have seen that in the case of capital there is likely to be no decrease in the total supply, but only a slackening in the rate of increase. In the case of labor the process of decreasing supply, that is of lowering population, is extremely slow. In the case of land there is no possibility of diminishing supply.

Let us return now to the question of demand for the factors of production. The analogy between the remuneration of the factors of production, and the payment of prices for consumers' goods, vanishes utterly when we reject the conception of capital as consisting of intermediate goods. There are reasons for regarding capital as simply the means of payment for hired labor. Use of capital means employment of labor. There is no choosing between labor and capital for the employer. He buys labor by means of capital. The choice apparently existing between the purchase of labor and of "capital goods" is really a choice between different kinds of labor. Instead of having three factors to choose from, the entrepreneur, therefore, appears to have only two. But, if we grant the existence of no-rent land and no-rent margins, we have the possibility 
of dispensing with the payment of a price for the use of land. Then there remains but one thing to buy for the entrepreneur, and that is labor. The entrepreneur (and the capitalist acting through the entrepreneur) must buy labor and it can be bought of the laborer only. The laborer, in his turn, must sell his labor, and it can be sold to the entrepreneur only. Instead of competing factors getting a price from a common purchaser, the process of distribution becomes a bargaining between two social classes. Both of them must ultimately come to terms, although the compelling forces on the two sides may be of very unequal urgency. Such a bargain may be covered by a very general and abstract theory of value and exchange, but all the really significant and interesting features disappear under such treatment. The attempt to approximate the theory of distribution to the more specialized theory of the values of commodities can only lead to confusion, and should be abandoned.

Like the excessively rationalistic, psychological character of modern economics, the tendency to confuse the problem of distribution and that of value, is also largely to be attributed to the influence of the Austrian theory of value. The enthusiasm with which the latter was received caused the ready acceptance of the analogous reasoning of the productivity theory. 
Indeed, the modern theorist felt most at ease when speculating on the subject of value. Every question in economics had perforce to be haled into this field. For the theory of distribution, however, the outcome was a distorted perspective and a failure to grasp the significant elements of the problem. 



89240

UC SOUTHERN REGIONAL LIBAARY FACILITY A
000687417 
